\title{
$\alpha 7$-Containing and Non- $\alpha$ 7-Containing Nicotinic Receptors Respond Differently to Spillover of Acetylcholine
}

\author{
Doychin Stanchev and Peter B. Sargent \\ Department of Cell and Tissue Biology and the Neuroscience Graduate Program, University of California, San Francisco, California 94143
}

We explored whether nicotinic acetylcholine receptors (nAChRs) might participate in paracrine transmission by asking if they respond to spillover of ACh at a model synapse in the chick ciliary ganglion, where ACh activates diffusely distributed $\alpha 7$ - and $\alpha 3$-containing nAChRs ( $\alpha 7$-nAChRs and $\alpha 3^{*}$-nAChRs). Elevating quantal content lengthened EPSC decay time and prolonged both the fast $(\alpha 7$-nAChRmediated) and slow ( $\alpha 3^{*}$-nAChR-mediated) components of decay, even in the presence of acetylcholinesterase. Increasing quantal content also prolonged decay times of pharmacologically isolated $\alpha 7$-nAChR- and $\alpha 3^{*}$-nAChR-EPSCs. The effect upon EPSC decay time of changing quantal content was 5-10 times more pronounced for $\alpha 3^{*}$-nAChR- than $\alpha 7$-nAChR-mediated currents and operated over a considerably longer time window: $\sim 20 \mathrm{vs} \sim 2 \mathrm{~ms}$. Control experiments rule out a presynaptic source for the effect. We suggest that $\alpha 3^{*}$-nAChR currents are prolonged at higher quantal content because of ACh spillover and postsynaptic potentiation (Hartzell et al., 1975), while $\alpha 7$-nAChR currents are prolonged probably for other reasons, e.g., increased occupancy of long channel open states. $\alpha 3^{*}$-nAChRs report more spillover when $\alpha 7$-nAChRs are competitively blocked than under native conditions; this could be explained if $\alpha 7$-nAChRs buffer ACh and regulate its availability to activate $\alpha 3^{*}$-nAChRs. Our results suggest that non- $\alpha 7$-nAChRs such as $\alpha 3^{\star}$ nAChRs may be suitable for paracrine nicotinic signaling but that $\alpha 7$-nAChRs may not be suitable. Our results further suggest that $\alpha 7$-nAChRs may buffer ACh and regulate its bioavailability.

\section{Introduction}

Nicotinic acetylcholine receptors (nAChRs) mediate rapid synaptic transmission in the peripheral nervous system. In the CNS nAChRs are thought to serve a modulatory role (Gotti and Clementi, 2004; Dani and Bertrand, 2007; Albuquerque et al., 2009). This thinking is based on several findings: cholinergic boutons are not usually located at synaptic sites (Umbriaco et al., 1994), nAChRs are often nonsynaptic (Fabian-Fine et al., 2001; Jones et al., 2001; Jones and Wonnacott, 2004), and activation of nAChRs by ACh modulates synaptic transmission or excitability (Mansvelder et al., 2002; Genzen and McGehee, 2003; Kawai et al., 2007; Wanaverbecq et al., 2007; Zhang and Berg, 2007).

The failure to find widespread evidence of colocalization of cholinergic boutons and nAChRs in the CNS has lead to the suggestion that nAChRs are involved in paracrine transmission, in much the same way that muscarinic AChRs function (Descar-

Received July 4, 2011; revised Aug. 24, 2011; accepted Sept. 1, 2011.

Author contributions: D.S. and P.B.S. designed research; D.S. and P.B.S. performed research; D.S. and P.B.S. analyzed data; P.B.S. wrote the paper.

This work was supported by NIH Grant R01 MH068690. We thank Philippe Ascher for many stimulating discussions, Steven Traynelis for assistance with ChannelLab, Michael McIntosh for the gift of $\alpha$-conotoxin MIl, Jackie Pisenti and the Avian Facility at University of California, Davis for supplying chick embryos, Tom Babcock for making Figure 1, and Philippe Ascher, Bill Betz, Tom Bartol, Jay Coggan, and Joseph Margiotta for comments on this manuscript.

The authors declare no competing financial interests.

Correspondence should be addressed to Dr. Peter B. Sargent, School of Dentistry Dean's Office, Box 0430, University of California, San Francisco, CA 94143-0430. E-mail: peter.sargent@ucsf.edu.

D. Stanchev's present address: Hertie-Institute for Clinical Brain Research, University of Tübingen, 72076 Tübingen, Germany.

DOI:10.1523/JNEUROSCI.3400-11.2011

Copyright $\odot 2011$ the authors $\quad 0270-6474 / 11 / 3114920-11 \$ 15.00 / 0$ ries et al., 1997; Vizi and Lendvai, 1999). However, at least two issues challenge acceptance of this notion: (1) the presence of acetylcholinesterase (AChE) at many sites of cholinergic projection (Mizukawa et al., 1986; but see Kawaja et al., 1990), and (2) the fact that nAChRs may not have a suitably low $\mathrm{EC}_{50}$ for $\mathrm{ACh}$. While volume transmission seems unlikely generally (Sarter et al., 2009), paracrine transmission may be feasible given the possible presence in brain of nAChRs with micromolar affinity for ACh (Zwart and Vijverberg, 1998; Nelson et al., 2003; Moroni et al., 2006).

Neuronal nAChRs comprise a diverse set of pentameric Cysloop receptors, which include heteromeric " $\alpha-\beta$ " nAChRs of several types as well as homomeric $\alpha 7$-nAChRs (Albuquerque et al., $2009)$. Recent evidence points to the participation of non- $\alpha 7$ nAChRs in paracrine transmission in the brain (Ren et al., 2011). $\alpha 7$-nAChRs might not be as well suited, since they desensitize rapidly (Bouzat et al., 2008); however, $\alpha 7$-nAChRs can be activated when singly bound (Rayes et al., 2009; Williams et al., 2011) and this, coupled with the presence of five presumptive binding sites for ACh, may allow them to respond to low concentrations of ACh and participate in paracrine signaling (Williams et al., 2011).

To explore the potential for $\alpha 7$-nAChRs and non- $\alpha 7$-nAChRs to participate in paracrine transmission we asked whether they respond to spillover of nerve-released $\mathrm{ACh}$ at a model calyciform synapse in the chick ciliary ganglion, where ACh acts on both $\alpha 7$-nAChRs and non- $\alpha 7$-nAChRs ( $\alpha 3$-containing nAChRs, or $\alpha 3^{*}$-nAChRs). We find that $\alpha 3^{\star}$-nAChRs readily "report" spillover of ACh, as evidenced by a broadening of synaptic currents at elevated quantal content (Hartzell et al., 1975), while $\alpha 7$-nAChR- 
mediated currents broaden only slightly. Curiously, when both $n A C h R s$ are active, $\alpha 3^{\star}$-nAChRs report less spillover than when $\alpha 7$-nAChRs are competitively blocked. Our results suggest that non$\alpha 7$-nAChRs may be suitable for paracrine transmission, even in the presence of acetylcholinesterase, but that $\alpha 7-\mathrm{nAChRs}$ may not be suitable; our results further suggest that $\alpha 7$-nAChRs may buffer $\mathrm{ACh}$ and regulate its availability to non- $\alpha 7-\mathrm{nAChRs}$.

\section{Materials and Methods}

Animals and materials. Animal procedures were done in accordance with the University of California, San Francisco Institutional Animal Care and Use Committee. Chick embryos of either sex were obtained from the Avian Facility at University of California, Davis and were housed in a forced draft incubator at $37-38^{\circ} \mathrm{C}$ and $50-55 \%$ relative humidity until $14-15 \mathrm{~d}$ of incubation (Hamilton-Hamburger stages 39-41). Embryos were killed by decapitation, and ciliary ganglia were dissected in HEPESbuffered saline (containing, in mM: $147.5 \mathrm{NaCl}, 4 \mathrm{KCl}, 2 \mathrm{CaCl}_{2}, 1 \mathrm{MgCl}_{2}$, 10 glucose, and 10 HEPES, pH 7.4, milliosmolarity: 310-315). Most experiments were performed in bicarbonate-buffered chick saline (containing, in mu: $130 \mathrm{NaCl}, 4 \mathrm{KCl}, 2 \mathrm{CaCl}_{2}, 1 \mathrm{MgCl}_{2}, 10$ glucose, 1 $\mathrm{Na}_{2} \mathrm{HPO}_{4}, 25 \mathrm{NaHCO}_{3}, \mathrm{pH}$ buffered to 7.4 by bubbling with $95 \% \mathrm{O}_{2}-5 \%$ $\mathrm{CO}_{2}$, milliosmolarity: 310-315). Peptide neurotoxins were applied in HEPES-buffered saline without oxygenation and in the presence of 0.1 $\mathrm{mg} / \mathrm{ml}$ protease-free bovine serum albumin. Internal solution contained the following (in mM): 120 Cs methanesulfonate, 15 TEA-Cl, 10 EGTA, 10 HEPES, 2 ATP, 0.2 GTP, and 5 QX-314, pH 7.2 (adjusted with CsOH), milliosmolarity: 295-305. Quantal content was varied by recording EPSCs at high $\left[\mathrm{Ca}^{2+}\right]_{\mathrm{e}}(5 \mathrm{~mm})$ and then by adding $25-50 \mu \mathrm{M} \mathrm{CdCl}_{2}$ or $\omega$-agatoxin GIVA to the bath.

$\alpha$-Conotoxin MII ( $\alpha$-CTx-MII) was kindly provided by $\mathrm{Dr}$. Michael McIntosh (University of Utah, Salt Lake City, UT). Echothiophate (ECHO) was kindly provided by Wyeth-Ayerst (now Pfizer). Other reagents were purchased from Sigma-Aldrich except methyllycaconitine (MLA) and QX-314 (Tocris Bioscience) and $\omega$-conotoxin GIVA (Invitrogen).

Electrophysiology. Neurons were prepared for whole-cell recording as described previously (Sargent, 2009) in a process that entails perfusion via a coarse patch pipette with a combination of collagenase and thermolysin (Liberase III, Roche). Because collagenase can release AChE from the extracellular matrix and prolong nicotinic synaptic currents (Hall and Kelly, 1971; Betz and Sakmann, 1973), we explored the extent to which currents at this synapse were prolonged by inhibitors of AChE and compared it with results from other nicotinic synapses that were not enzyme-treated. The decay time (defined as $\tau_{\mathrm{w}}$, see below) of native EPSCs, produced by the activation of both $\alpha 7-\mathrm{nAChRs}$ and $\alpha 3^{*}$ nAChRs, was prolonged 2.9-fold by $10 \mu \mathrm{M} \mathrm{ECHO}(n=8$ cells, $p=0.02)$. The decay time of pharmacologically isolated $\alpha 3^{\star}$-nAChR EPSCs (produced by blocking $\alpha 7$-nAChRs with 50 nM MLA) was increased 3.6-fold $(n=12, p<0.0001)$. The broadening of EPSCs seen here is similar to the 2.5- to 3.5-fold broadening of synaptic currents reported in rat submandibular cells after inhibition of AChE by Rang (1981), who used sharp electrodes and did not expose cells to enzyme. This suggests that enzyme treatment of ciliary neurons does not remove enough AChE from the synaptic cleft to have obvious effects on EPSC time course.

Whole-cell recordings in voltage-clamp mode were made from ciliary neurons according to standard procedures using an Axopatch 200B amplifier (Molecular Devices) as described previously (Sargent, 2009). Neurons were usually held at $-60 \mathrm{mV}(-74 \mathrm{mV}$, when corrected for the calculated liquid junction potential of $-14 \mathrm{mV}$ ). Series resistance was monitored during the recording, and experiments were discontinued if total series resistance exceeded $10 \mathrm{M} \Omega$ or if the current required to hold the cell at $-60 \mathrm{mV}$ exceeded $-100 \mathrm{pA}$. Series resistance compensation $(80 \%)$ was used using the Axopatch 200B, and in a few instances the remaining series resistance error was eliminated subsequently using the method of Traynelis (1998) as implemented in ChannelLab (Synaptosoft) and using a correction for a nonlinear IV curve (Sargent, 2009). Synaptic currents were analyzed using Neuromatic (www.neuromatic.thinkrandom.com, Jason Rothman)

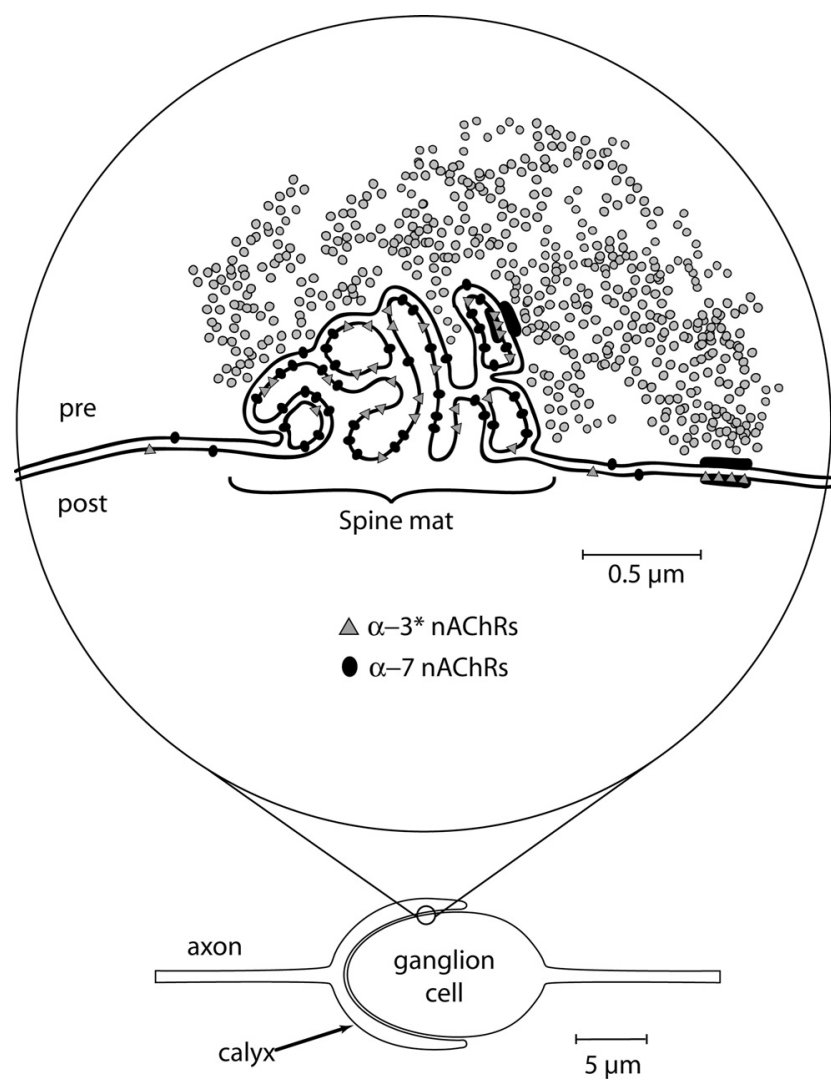

Figure 1. Schematic of the calyciform synapse in the chick ciliary ganglion. Low magnification view (bottom) is of a ciliary neuron with its calyciform (calyx-like) input. Highmagnification view (top) is of a spine mat, showing a clump of interdigitating spines cut in cross-section (Shoop et al., 2002). One synaptic contact is shown on the soma and a second on a spine. $\alpha 3^{*}$-nAChRs (light gray triangles) are clustered at PSDs, and both $\alpha 3^{*}$-nAChRs and $\alpha 7$-nAChRs (dark gray ovals) are diffusely distributed in the extrasynaptic membrane on spines. Transmitter release may be active zone based (Nguyen and Sargent, 2002) and/or ectopic (Coggan et al., 2005); in either case the functional receptors recognized by ACh are largely extrasynaptic and located on spines (Sargent, 2009).

implemented in Igor Pro (Wavemetrics). Experiments were done at room temperature $\left(21-23^{\circ} \mathrm{C}\right)$.

EPSC "rise time" in the text is $10-90 \%$ rise time. EPSC decay was calculated as the time constant $(\tau)$ of a mono- or biexponentially decaying function. For the biexponential function, $I=A_{\mathrm{f}} \cdot\left(e^{\left(-\left(t-t_{0}\right) / \tau_{\mathrm{f}}\right)}\right)+$ $A_{\mathrm{s}} \cdot\left(e^{\left(-\left(t-t_{0}\right) / \tau_{\mathrm{s}}\right)}\right)$, where $A_{\mathrm{f}}$ and $A_{\mathrm{s}}$ are the amplitudes of the rapidly and slowly decaying components of current, $\tau_{\mathrm{f}}$ and $\tau_{\mathrm{s}}$ are the time constants of decay, and $\mathrm{t}_{0}$ is the time from which the fit begins. The weighted $\tau$ for biexponential fits, $\tau_{\mathrm{w}}$, is equal to $\tau_{\mathrm{f}}\left(A_{\mathrm{f}} / A\right)+\tau_{\mathrm{s}}\left(A_{\mathrm{s}} / A\right)$, where $A=A_{\mathrm{f}}+A_{\mathrm{s}}$.

The "sensitivity" of EPSC decay to changes in quantal content was assessed as $\Delta \tau_{\mathrm{w}} / \Delta A$, with $\tau_{\mathrm{w}}$ and $A$ defined as above, before and after EPSCs were partially blocked by $25-50 \mu \mathrm{M}$ cadmium, with each measurement derived from an average of 3-5 consecutive EPSCs. When only one component of decay was present, sensitivity was measured as $\Delta \tau_{\mathrm{f}} / \Delta A_{\mathrm{f}}$ or $\Delta \tau_{\mathrm{s}} / \Delta A_{\mathrm{s}}$. By using current amplitude as a measure of quantal content we are assuming that quantal content is linearly related to peak response. Spillover may result in a nonlinear relationship between quantal content and current amplitude, and thus our assumption about linearity may not strictly be true; however, this does not change the interpretation of our results.

AChE was inhibited by exposure to either $10 \mu \mathrm{M}$ ECHO or $0.1 \mu \mathrm{M}$ neostigmine for $>10 \mathrm{~min}$. Native EPSCs treated with ECHO or with neostigmine had similar amplitudes $(p=0.6)$, rise times $(p=0.1)$, and decay times ( $p=0.9$; all comparisons by unpaired $t$ test); in the Results section, we treat ECHO and neostigmine as equivalent. ECHO blocks $\sim 90 \%$ of AChE in the ganglion under the conditions used (Rogers and Sargent, 2003). 


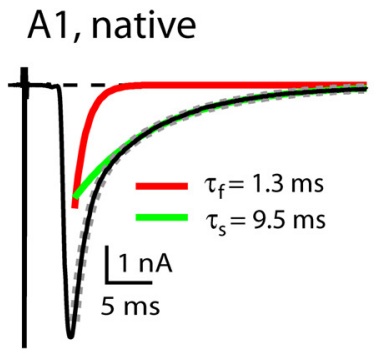

- EPSC

$\square= \pm$ biexponential fit
A2a

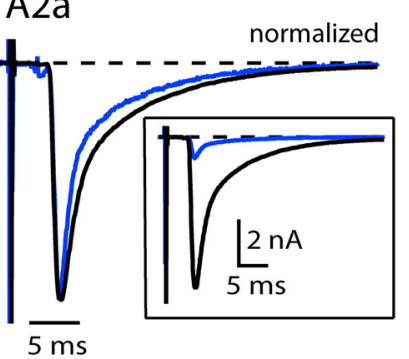

$A 2 b$

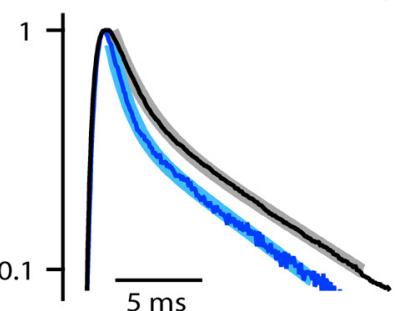

$5 \mathrm{~ms}$

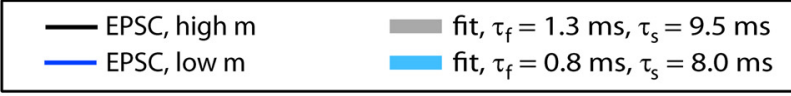

B2a

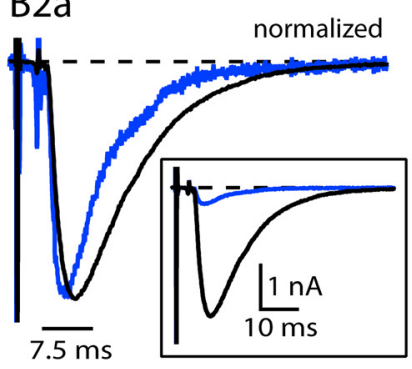

B2b normalized, semi-log

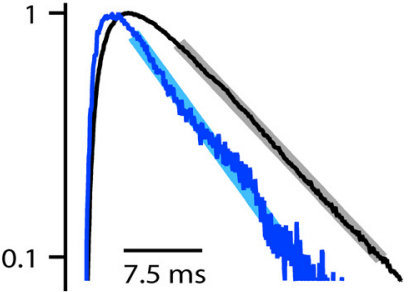

B3

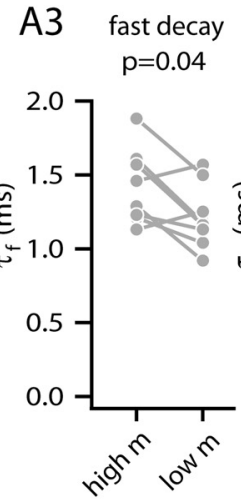

slow decay

$\mathrm{p}=0.0001$

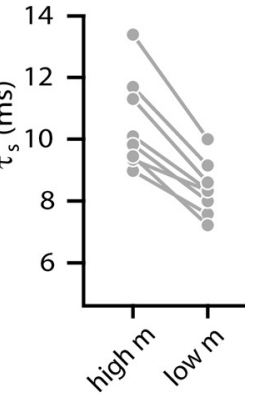

B3
B1, plus MLA

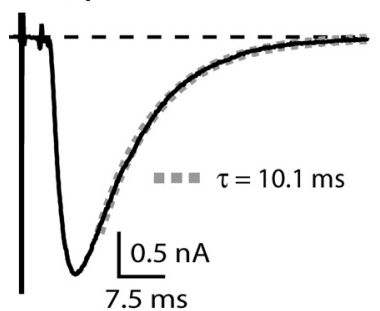

EPSC

$\because=$ monoexponential fit

\begin{tabular}{|ll|}
\hline EPSC, high $\mathrm{m}$ & fit, $\tau_{\mathrm{s}}=10.1 \mathrm{~ms}$ \\
EPSC, low $\mathrm{m}$ & fit, $\tau_{\mathrm{s}}=7.8 \mathrm{~ms}$
\end{tabular}

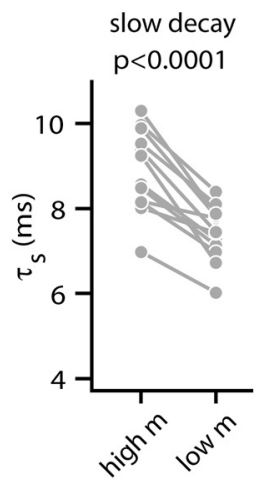

\section{C1, plus $\alpha-C T x-M I I$}

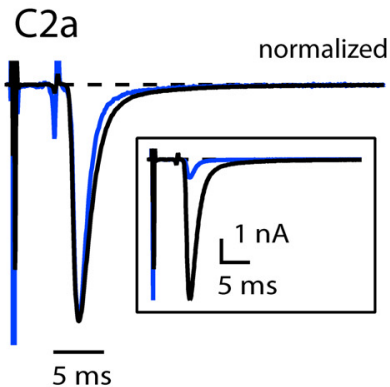

$\mathrm{C} 2 \mathrm{~b}$ normalized, semi-log

\section{C3}
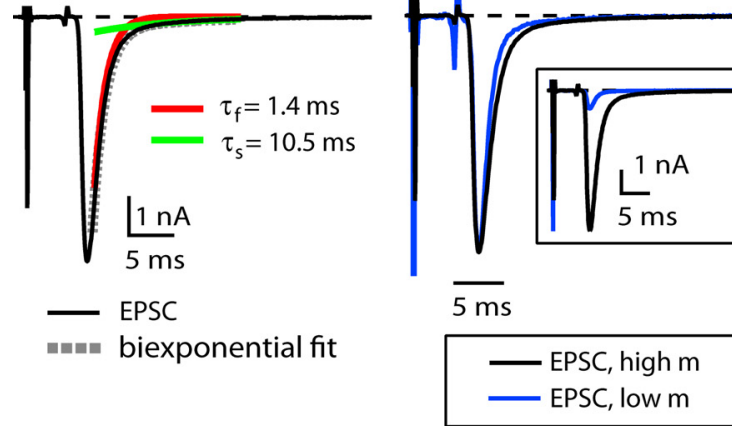
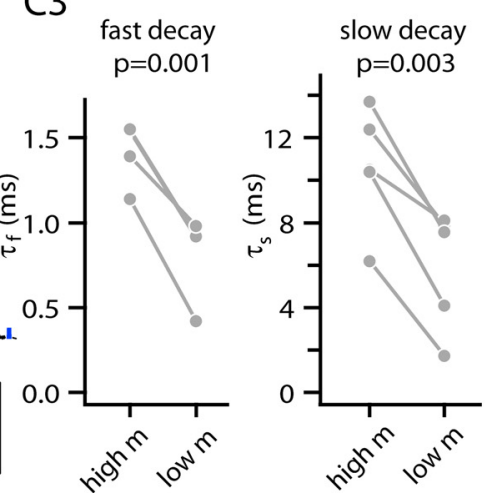

Figure 2. Changing quantal content alters EPSC decay mediated by both $\alpha 3^{*}$-nAChRs and $\alpha 7$-nAChRs. $A-C$ show results for native EPSCs $(\boldsymbol{A}), \alpha 3^{*}$-nAChR-EPSCs (B), and $\alpha 7$-nAChR-EPSCs $(\boldsymbol{C})$. $A 1$ shows a native EPSC (each trace is the average of $3-5$ consecutive responses) with a decay that is well fit by the sum of two exponential functions: a fast $\tau_{\mathrm{f}}$ of $1.3 \mathrm{~ms}$ (red, $\alpha 7$-nAChRs) and a slow $\tau_{\mathrm{s}}$ of $9.5 \mathrm{~ms}$ (green, $\alpha 3^{*}$-nAChRs). $\mathbf{A 2} \boldsymbol{a}$ and $\boldsymbol{A} \mathbf{2} \boldsymbol{b}$ show normalized traces at high and low quantal content, illustrating that both decay components are prolonged at high quantal content (inset in $\boldsymbol{A} \mathbf{2} \boldsymbol{a}$ shows traces before normalization). $\mathbf{A} \mathbf{2} \boldsymbol{b}$ shows fits on a semilog graph with the currents reversed in sign. The legend for $\boldsymbol{A} \mathbf{2}$ and $\tau$ values for the fits in $\boldsymbol{A} \mathbf{2} \boldsymbol{b}$ are shown in the box beneath the figure. $\mathbf{A}$ shows data summary for $\tau_{\mathrm{f}}$ (left) and $\tau_{\mathrm{s}}$ (right), both of which are reduced significantly at low quantal content (low $\mathrm{m}$ ). $\boldsymbol{B}$ shows the same set of graphs as in $\boldsymbol{A}$, except that recordings made in $50 \mathrm{~nm}$ MLA to block $\alpha 7$-nAChRs; EPSCs are thus $\alpha 3^{*}$-nAChR-EPSCs. EPSC decay is usually well fit by a single exponentially decaying function $\left(\tau_{\mathrm{s}}\right)$, and thus there is no graph in $B 3$ for fast decay. C shows the same set of graphs as in $A$, except that recordings were made in $0.3 \mu \mathrm{M} \alpha$-CTX-MII, which blocks $\sim 90 \%$ of $\alpha 3^{*}$-nAChRs. EPSCs recorded in $\alpha$-CTx-MIl show a small amount of residual $\alpha 3^{*}$-nAChR-mediated current (green trace in $\mathbf{C}$ ). Both $\tau_{\mathrm{f}}$ and $\tau_{\mathrm{s}}$ are again reduced at low quantal content, as for native EPSCS $(\boldsymbol{A})$. C 3 , left, contains 5 data pairs but appears to contain only 3 , due to data point superposition.

Statistical tests were made using PAST.exe (http://folk.uio.no/ohammer/past/index.html). Sample errors are given as SD, and samples were compared using the paired Student's $t$ test, unless otherwise noted.

Control experiments. One of the principal findings in Results is that reducing the quantal content of EPSCs with cadmium shortens decay time, and we will argue that this is the result of a reduction in quantal content mediated by blocking calcium channels in the nerve terminal. The possibility that the quantal response itself is altered in time course by cadmium is unlikely, since uniquantal evoked responses recorded in cadmium are similar in shape to mEPSCs recorded in the absence of cad- mium (Sargent, 2009). This same finding argues against the possibility that the effect is due to a direct action of cadmium on nAChR channels; moreover, we get the same effect on EPSC decay time when we block calcium channels with $\omega$-agatoxin GIVA instead of cadmium (data not shown). The possibility that the latency function (release probability vs time) is altered in cadmium is unlikely, since changes in decay time are not accompanied by a change in native EPSC rise time. To explore whether EPSC decay is affected by changing quantal size, unaccompanied by changes in quantal content, we reduced the holding potential from $-60 \mathrm{mV}$ to $-20 \mathrm{mV}$ (from $-74 \mathrm{mV}$ to $-34 \mathrm{mV}$, when a correction 
Table 1. Fitted decay time constants $\left(\tau_{\mathrm{f}}\right.$ and $\left.\tau_{\mathrm{s}}\right)$ and weights $\left(A_{\mathrm{f}}\right.$ and $\left.A_{\mathrm{s}}\right)$ for fast $(\mathrm{f})$ and slow $(\mathrm{s})$ phases of EPSC decay under conditions of high and low quantal content ( $\mathrm{m}$ )

\begin{tabular}{|c|c|c|c|c|c|c|c|c|c|c|c|c|}
\hline & \multicolumn{6}{|c|}{$\tau_{\mathrm{f}}(\alpha 7-\mathrm{nAChRs})$} & \multicolumn{6}{|c|}{$\tau_{\mathrm{s}}\left(\alpha 3^{*}\right.$-nAChRs) } \\
\hline & \multicolumn{2}{|l|}{ Native EPSCs } & \multicolumn{2}{|c|}{$\alpha 7$-nAChR EPSCs in $\alpha$-CTx-MII } & \multicolumn{2}{|c|}{$\begin{array}{l}\alpha 3^{*} \text {-nAChR } \\
\text { EPSCs in MLA }{ }^{a}\end{array}$} & \multicolumn{2}{|l|}{ Native EPSCs } & \multicolumn{2}{|c|}{$\alpha 7$-nAChR EPSCs in $\alpha$-CTx-MII ${ }^{b}$} & \multicolumn{2}{|c|}{$\alpha 3^{*}$-nAChR EPSCs in MLA } \\
\hline & $\tau_{\mathrm{f}}(\mathrm{ms})$ & $A_{\mathrm{f}}(\mathrm{nA})$ & $\tau_{\mathrm{f}}(\mathrm{ms})$ & $A_{\mathrm{f}}(\mathrm{nA})$ & $\tau_{\mathrm{f}}(\mathrm{ms})$ & $A_{\mathrm{f}}(\mathrm{nA})$ & $\tau_{\mathrm{s}}(\mathrm{ms})$ & $A_{\mathrm{s}}(\mathrm{nA})$ & $\tau_{\mathrm{s}}(\mathrm{ms})$ & $A_{\mathrm{s}}(\mathrm{nA})$ & $\tau_{\mathrm{s}}(\mathrm{ms})$ & $A_{\mathrm{s}}(\mathrm{nA})$ \\
\hline High m & $\begin{array}{l}1.42 \pm 0.25 \\
n=8\end{array}$ & $2.9 \pm 0.9$ & $\begin{array}{l}1.40 \pm 0.17 \\
n=5\end{array}$ & $4.2 \pm 1.6$ & - & - & $\begin{array}{l}10.5 \pm 1.5 \\
n=8\end{array}$ & $3.5 \pm 0.7$ & $\begin{array}{l}10.6 \pm 2.8 \\
n=5\end{array}$ & $0.30 \pm 0.08$ & $\begin{array}{l}8.9 \pm 1.0 \\
n=12\end{array}$ & $2.0 \pm 1.1$ \\
\hline Low m & $\begin{array}{l}1.22 \pm 0.22 \\
n=8\end{array}$ & $0.6 \pm 0.2$ & $\begin{array}{l}0.84 \pm 0.24 \\
n=5\end{array}$ & $0.5 \pm 0.3$ & - & - & $\begin{array}{l}8.4 \pm 0.9 \\
n=8\end{array}$ & $0.7 \pm 0.3$ & $\begin{array}{l}5.9 \pm 2.8 \\
n=5\end{array}$ & $0.07 \pm 0.06$ & $\begin{array}{l}7.4 \pm 0.6 \\
n=12\end{array}$ & $0.4 \pm 0.2$ \\
\hline $\begin{array}{c}\text { Ratio (low m/ } \\
\text { high m) }\end{array}$ & $\begin{array}{l}0.87 \pm 0.15 \\
p=0.04\end{array}$ & $\begin{array}{l}0.21 \pm 0.08 \\
p=0.0001\end{array}$ & $\begin{array}{l}0.59 \pm 0.14 \\
p=0.001\end{array}$ & $\begin{array}{l}0.10 \pm 0.03^{c} \\
p=0.003\end{array}$ & - & - & $\begin{array}{l}0.80 \pm 0.05 \\
p=0.0001\end{array}$ & $\begin{array}{l}0.20 \pm 0.06 \\
p<0.0001\end{array}$ & $\begin{array}{l}0.53 \pm 0.19 \\
p=0.003\end{array}$ & $\begin{array}{l}0.23 \pm 0.12^{c} \\
p=0.0007\end{array}$ & $\begin{array}{l}0.84 \pm 0.06 \\
p<0.0001\end{array}$ & $\begin{array}{l}0.22 \pm 0.11 \\
p=0.0002\end{array}$ \\
\hline
\end{tabular}

$p$ values in the bottom row refer to results of the paired $t$ test, comparing high and low $m$ conditions.

${ }^{a}$ MLA at 50 nm blocks $\sim 100 \%$ of $\alpha 7$-nAChRs, and so EPSCs have no rapid component of decay in MLA.

${ }^{b} \alpha$-CTx-MIl at $0.3 \mu$ m blocks $90 \%$ of $\alpha 3^{*}$-nAChRs, and thus, EPSCs still have a detectable component of slow decay in $\alpha$-CTx-MII (see Fig. 2 C1).

'The degree of block of current amplitudes in cadmium may differ across experiments because EPSCs selected for the low quantal content condition were not invariably exposed to the same concentration of cadmium.

is made for the liquid junction potential); this reduced EPSCs by $56 \pm 2 \%$ but had no effect on EPSC decay $(n=4, p=0.2)$. In addition, partially blocking $\alpha 3^{*}$-nAChR-EPSCs (EPSCs recorded in 50 nм MLA) with the competitive $\mathrm{nAChR}$ antagonist dihydro- $\beta$-erythroidine did not change EPSC decay (data not shown). These results suggest that EPSC decay is influenced by changes in quantal content, but not by changes in quantal size.

To demonstrate that the broadening of kinetically fast $\alpha 7$-nAChREPSCs (recorded in $\alpha$-CTx-MII) at high quantal content is not due to the residual 20\% series resistance error, we corrected off-line for the remainder of the error (0.5-1 M $\Omega$ ) using ChannelLab (Traynelis, 1998). Full correction of $\alpha 7$-nAChR-EPSCs increased their amplitude and shortened their decay time constants (data not shown). Fully corrected $\alpha 7$ nAChR-EPSCs still had a faster $\tau$ values for decay at low quantal content than at high quantal content (data not shown). Thus, residual series resistance errors do not contribute to the effect of changing quantal content upon $\tau_{\mathrm{f}}$. Finally, to demonstrate that the broadening of $\alpha 7$ nAChR-EPSCs at high quantal content is not due to a contribution from residual $\alpha 3^{*}$-nAChR-mediated current that survives $0.3 \mu \mathrm{M} \alpha$-CTx-MII (see Fig. 2C1), we calculated the residual $\alpha 3$-nAChR current likely to be present in $0.3 \mu \mathrm{M} \alpha$-CTx-MII and subtracted it from total current to generate "pharmacologically cleaned" $\alpha 7$-nAChR-mediated currents. Pharmacologically cleaned $\alpha 7$-nAChR-EPSCs still showed shorter decay time constants in cadmium compared with high quantal conditions (data not shown).

\section{Results}

We explored whether $\alpha 7$-nAChRs and $\alpha 3^{*}$-nAChRs respond to spillover of $\mathrm{ACh}$ at the calyciform synapse by noting whether changing quantal content produced systematic changes in EPSC decay. We define "spillover" as the ability of ACh to reach nAChRs not directly opposite sites of release (non-focal sites). Our approach mimics that of Hartzell et al. (1975), who found that synaptic currents decay more slowly at elevated quantal content when ACh released in separate quanta reaches common areas of the postsynaptic membrane. This effect, which Hartzell et al. (1975) called "postsynaptic potentiation," results from the fact that the interaction of ACh at low concentration with its receptor operates in the supralinear part of the dose-response curve.

Figure 1 shows a schematic of the chick calyciform synapse at embryonic day 15. Our current understanding of this synapse, perhaps the best characterized interneuronal nicotinic synapse, comes from a combination of anatomical, physiological, and modeling studies (Jacob and Berg, 1983; Loring and Zigmond, 1987; Horch and Sargent, 1995; Zhang et al., 1996; Ullian et al., 1997; Shoop et al., 1999; Conroy et al., 2003; Coggan et al., 2005; Sargent, 2009). The synapse contains $\sim 500$ contacts, of which $\sim 10 \%$ are located on spine mats, which are widely distributed over the cell surface. $\alpha 3^{*}$-nAChRs are clustered at PSDs, but these $n A C h R s$ do not contribute significantly to the EPSC. Most of the response to nerve-released ACh is generated by the coactivation of $\alpha 7$-nAChRs and $\alpha 3^{*}$-nAChRs; since $\alpha 7$-nAChRs are found preferentially on spines, most of the synaptic current is presumably generated by ACh release onto spines, where it acts on diffusely distributed $\alpha 7$-nAChRs and $\alpha 3^{\star}$-nAChRs (Fig. 1).

\section{$\alpha 7-n A C h R s$ and $\alpha 3^{\star}-n A C h R s$ differ in their response to changes in quantal content}

To explore whether $\alpha 7$-nAChRs and $\alpha 3^{*}$-nAChRs respond differently to changes in quantal content, we took advantage of differences in their channel kinetics (Zhang et al., 1996; Ullian et al., 1997; McNerney et al., 2000; Nai et al., 2003) and fit EPSC decays to the sum of two exponentially decaying functions, fast ( $\alpha 7$ $\mathrm{nAChR})$ and slow $\left(\alpha 3^{\star}\right.$-nAChR), under conditions of high and low quantal content. Figure $2 \mathrm{~A} 1$ shows a biexponential fit (dotted gray line) to an EPSC recorded in $5 \mathrm{~mm}\left[\mathrm{Ca}^{2+}\right]_{\mathrm{e}}$; in this example, the time constants for the fast $\left(\tau_{\mathrm{f}}\right.$, red) and slow $\left(\tau_{\mathrm{s}}\right.$, green) phases of decay were $1.3 \mathrm{~ms}$ and $9.5 \mathrm{~ms}$. Over a sample of 8 cells, $\tau_{\mathrm{f}}$ and $\tau_{\mathrm{s}}$ were $1.42 \pm 0.25 \mathrm{~ms}$ and $10.5 \pm 1.5 \mathrm{~ms}$ and similar to those reported earlier (Zhang et al., 1996; Ullian et al., 1997). After addition of $50 \mu \mathrm{M} \mathrm{Cd}{ }^{2+}$, EPSC amplitude was reduced $>7$-fold (Fig. $2 A 2 a$, inset), and both the fast and slow components of decay were shortened: $\tau_{\mathrm{f}}$ was reduced from 1.3 to $0.8 \mathrm{~ms}$, and $\tau_{\mathrm{s}}$ was reduced from 9.5 to $8.0 \mathrm{~ms}$ (Fig. $2 \mathrm{~A} 2 \mathrm{~b}$ ). Over 8 experiments, both $\tau_{\mathrm{f}}$ and $\tau_{\mathrm{s}}$ were reduced significantly when quantal content was lowered: $\tau_{\mathrm{f}}$ was reduced by $13 \pm 15 \%(p=$ 0.04 , Fig. $2 A 3$, left $)$ and $\tau_{\mathrm{s}}$ was reduced by $20 \pm 5 \%(p=0.0001$; Fig. $2 A 3$, right). Fitted $\tau$ values are summarized in Table 1 along with the current amplitudes $(A)$. Rise time was not affected $(0.73 \pm 0.06 \mathrm{~ms}$ at high quantal content, $p=0.8)$. This suggests that currents mediated by both $\alpha 7$-nAChRs and $\alpha 3^{*}$-nAChRs decay more rapidly when quantal content is reduced. In the presence of cadmium, EPSCs were generally $0.5-1.0 \mathrm{nA}$ in amplitude and multiquantal, since mEPSCs are $\sim 50 \mathrm{pA}$ in amplitude (Sargent, 2009). Spontaneously occurring mEPSCs and uniquantal evoked responses are yet faster that the multiquantal EPSCs recorded in cadmium and shown here (Sargent, 2009).

To improve the resolving power of our approach, we repeated the experiments after blocking $\alpha 7$-nAChRs or $\alpha 3^{\star}$-nAChRs to produce pharmacologically enriched " $\alpha 3^{\star}$-nAChR-EPSCs" or " $\alpha 7$-nAChR-EPSCs," respectively. When $\alpha 7$-nAChRs are fully blocked by $50 \mathrm{~nm}$ MLA, $\alpha 3^{\star}$-nAChR-EPSC decay in $5 \mathrm{~mm}$ $\left[\mathrm{Ca}^{2+}\right]_{\mathrm{e}}$ was well fit usually with a single exponential function having a time constant of $8.9 \pm 1.0 \mathrm{~ms}$ (in 10 of 12 cells; in two cells a second, longer $\tau$ was present); this $\tau$ was comparable to the slow phase of decay, $\tau_{s}$, in native EPSCs. At low quantal content this $\tau$ was reduced by $16 \pm 6 \%(p<0.0001 ;$ Fig. 2 B3 $)$. Figure $2, B 1$ 
and B2, shows an experiment where this $\tau$ was shorted from $10.1 \mathrm{~ms}$ to $7.8 \mathrm{~ms}$ by reducing quantal content. Addition of cadmium also shortened the rise time of $\alpha 3^{*}$-nAChR-EPSCs by $24 \pm 13 \%$ (from $2.38 \pm 0.41 \mathrm{~ms}, p=0.003)$.

When $\alpha 3^{\star}$-nAChRs were $90 \%$ blocked by $0.3 \mu \mathrm{M} \alpha$-CTx-MII, resultant $\alpha 7$-nAChR EPSCs decayed biexponentially, with a small component of slowly decaying current arising from residual, unblocked $\alpha 3^{\star}$-nAChRs (Fig. 2C1, green; compare with Fig. 2A1). At high quantal content these $\alpha 7-n A C h R-$ EPSCs had a $\tau_{\mathrm{f}}$ of $1.40 \pm 0.17 \mathrm{~ms}$ and a $\tau_{\mathrm{s}}$ of $10.6 \pm 2.8 \mathrm{~ms}$ (not different from $\tau$ values for native EPSCs, $p>0.8$ by unpaired $t$ test). Reducing quantal content significantly reduced both $\tau_{\mathrm{f}}$ and $\tau_{\mathrm{s}}$ (Fig. 2C3); $\tau_{\mathrm{f}}$ was reduced by $41 \pm 14 \%(p=0.001)$, and $\tau_{\text {s }}$ was reduced by $47 \pm 19 \%(p=0.003)$. Figure 2 , $C 1$ and $C 2$, shows an example from a cell where cadmium reduced $\tau_{\mathrm{f}}$ from 1.4 to 1.0 $\mathrm{ms}$ and $\tau_{\mathrm{s}}$ from $10.5 \mathrm{~ms}$ to $8.1 \mathrm{~ms}$. Addition of cadmium did not affect the rise time $(p=0.11)$, which is consistent with results on native EPSCs, where rise time is dominated by the $\alpha 7$-nAChR current. In summary, changing quantal content alters the decay of synaptic currents generated by activation of both $\alpha 7$ nAChRs and $\alpha 3^{*}$-nAChRs (Table 1). Rise time is altered for $\alpha 3^{*}-\mathrm{nAChR}$ EPSCs but not for $\alpha 7$-nAChR-EPSCs.

One possible basis for the systematic change in the decay of currents mediated by $\alpha 7$-nAChRs and $\alpha 3^{\star}$-nAChRs is spillover; by analogy with the work of Hartzell et al. (1975), elevating quantal content allows ACh from separate quanta to reach overlapping areas of postsynaptic membrane; this, coupled with the nonlinear dose-response curve for nAChRs, produces postsynaptic potentiation (Hartzell et al., 1975). In control experiments (see Materials and Methods) we rule out a presynaptic source for the changes in EPSC time course produced by changes in quantal content.

The sensitivity of synaptic currents to changes in quantal content, expressed as change in decay $\tau$ (ms) per unit change in amplitude (nA), is markedly greater for $\alpha 3^{\star}$-nAChRs than for $\alpha 7-n A C h R s$, as can be seen qualitatively by comparing the normalized traces at high and low quantal content (Fig. $2 B 2 a$ vs Fig. $2 C 2 a)$. The sensitivity of $\tau_{s}\left(\alpha 3^{\star}\right.$ nAChRs) to changes in quantal content is $0.76 \pm 0.28 \mathrm{~ms} / \mathrm{nA}$ when measured on native EPSCs and $1.20 \pm 0.84 \mathrm{~ms} / \mathrm{nA}$ when measured on $\alpha 3^{\star}$-nAChR EPSCs recorded in 50 nM MLA ( $p=$ 0.2 by unpaired $t$ test). The sensitivity of $\tau_{\mathrm{f}}(\alpha 7-\mathrm{nAChRs})$ is $5-10$ times smaller: $0.09 \pm 0.11 \mathrm{~ms} / \mathrm{nA}$ when measured on native EPSCs $(p=0.0005)$ and $0.18 \pm 0.10 \mathrm{~ms} / \mathrm{nA}$ when measured on $\alpha 7$-nAChR EPSCs recorded in $0.3 \mu \mathrm{M} \alpha$-CTx-MII $(p=0.02$, unpaired $t$ test).

B1
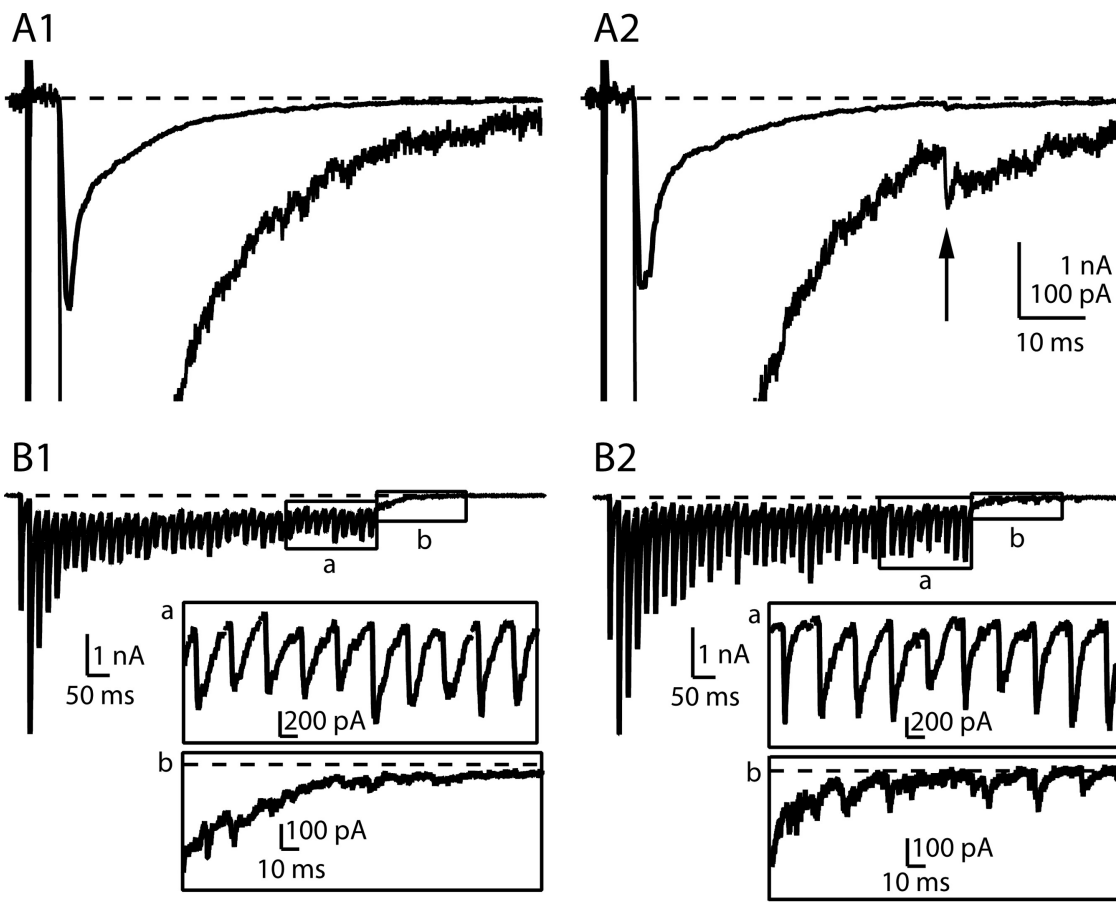

B2
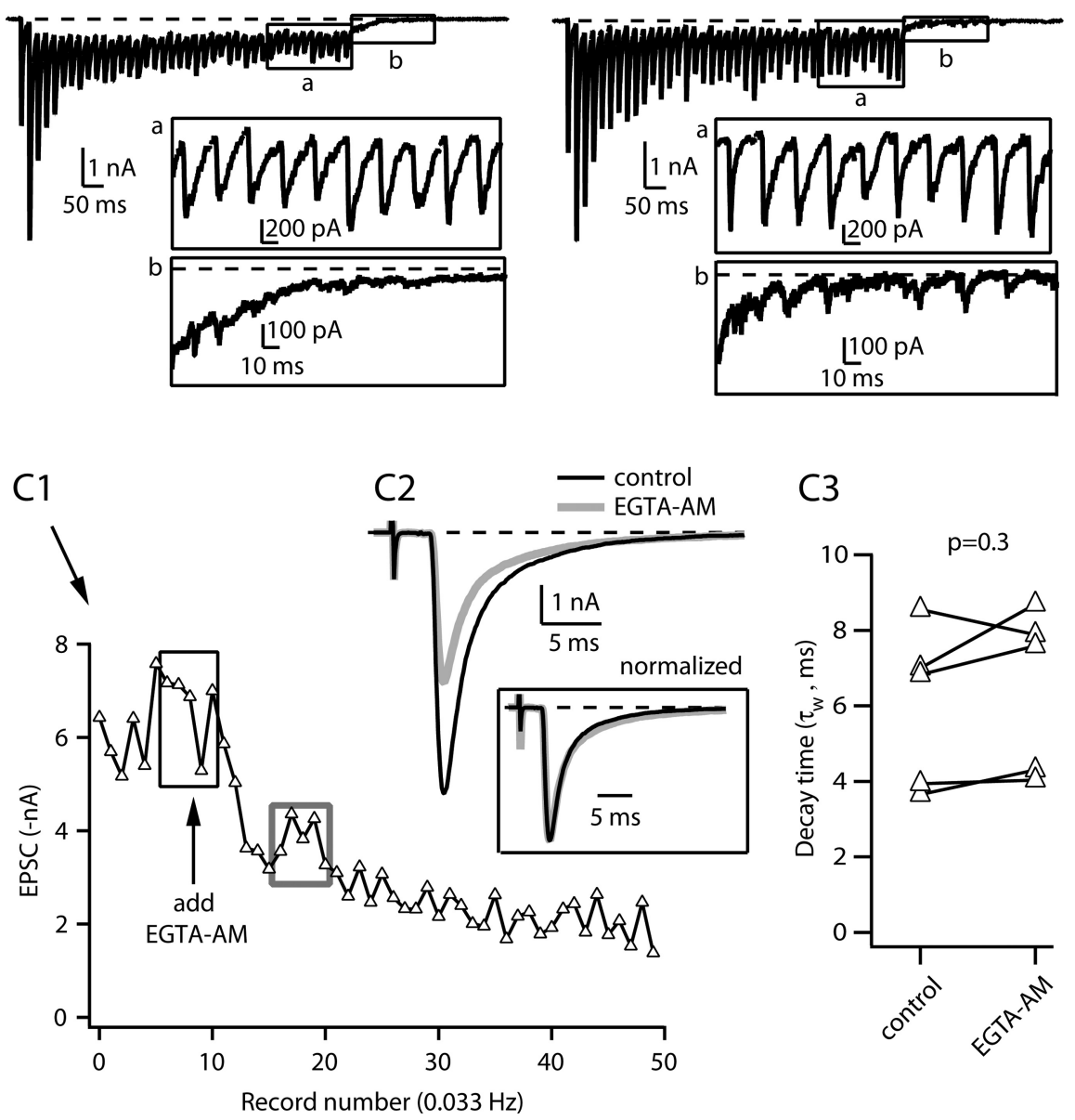

Figure 3. Delayed/asynchronous release is not prominent at the calyciform synapse in the chick ciliary ganglion. Traces $\boldsymbol{A} 1$ and A2 show typical EPSCS at both low and high gain (scale is in A2). Arrow in $\mathbf{A 2}$ identifies a delayed release event, assumed to be monoquantal. MEPSC frequency normally is $<0.1 \mathrm{~Hz}$ (Sargent, 2009). $\boldsymbol{B} 1$ and $\boldsymbol{B} 2$ show responses to trains of 40 stimuli delivered at $50 \mathrm{~Hz}$ (examples from two different cells), with insets showing higher gain at the end of the train (a) and after the end of the train (b). Transmitter release remains largely synchronous at the end of the train (inset $\boldsymbol{a}$ ), and asynchronous events after the end of the train are not common (inset $\boldsymbol{b}$ ). (1 shows peak EPSC amplitude (evoked at $0.033 \mathrm{~Hz}$ ) as EGTA-AM is added to the bath; peak response declines, but time course is not altered substantially (C2). EPSCs in $\mathbf{C} 2$ were generated from averages of five consecutive responses, indicated by boxes in C1. EPSC decay time, measured as $\tau_{w^{\prime}}$ is not altered over a sample of five cells (C3). A $10 \%$ reduction in decay time would be expected on the basis of the effect of EGTA-AM on quantal content (see Results for details).

Prolongation of EPSCs at high quantal content is not due to delayed release

We performed three experiments to address the possibility that delayed/asynchronous release, which is calcium dependent (Atluri and Regehr, 1998; Oleskevich and Walmsley, 2002), underlies the prolongation of EPSC decay time at high quantal content. In the first, we looked for evidence of delayed release late in the falling phase of individual EPSCs and at the end of a stimulus train. Delayed release is difficult to detect during the steeply de- 
caying part of the EPSC. Between 20 and $40 \mathrm{~ms}$ after the EPSC peak, however, when the current approaches baseline and when individual quantal events are readily detectable, we found that delayed release events were uncommon and occurred at an overall frequency of $1.0 \mathrm{~Hz}$ (Fig. 3A1,A2; $n=8$ cells, $15-100$ trials per cell).

Delayed release is enhanced by increasing the number of stimuli (Atluri and Regehr, 1998; Hagler and Goda, 2001); we therefore noted the effect of trains of 40 stimuli at $50 \mathrm{~Hz}$ on the appearance of delayed release, which should be especially evident at and after the end of the train. Figure $3 B$ shows typical responses, collected in $2 \mathrm{~mm}\left[\mathrm{Ca}^{2+}\right]_{\mathrm{e}}$ and $1 \mathrm{~mm}\left[\mathrm{Mg}^{2+}\right]_{\mathrm{e}}$, to $50 \mathrm{~Hz}$ stimulation. Virtually all release during the train is synchronous, although a few asynchronous events are evident (Fig. 3B, insets). Similar results were obtained in six other cells. These findings suggest that delayed release is not a prominent feature of transmission at this synapse.

If delayed release contributes significantly to the falling phase of EPSCs, then reducing bulk calcium in the nerve terminal should shorten EPSC decay. We thus explored the effect of EGTA-AM, which should block delayed release more readily than synchronous release after permeating the terminal and being hydrolyzed to EGTA (Atluri and Regehr, 1998; Hagler and Goda, 2001; Otsu et al., 2004). Addition of $50 \mu \mathrm{M}$ EGTA-AM to cells bathed in $5 \mathrm{~mm}\left[\mathrm{Ca}^{2+}\right]_{\mathrm{e}}$ reduced EPSC size (Fig. $3 \mathrm{Cl}$ ) but did not shorten decay time significantly (Fig. $3 C 2, C 3, n=5$ cells, $p=$ 0.3 ). Since EGTA-AM reduced synchronous release, we expected to see a reduction in EPSC decay solely because of its reduction of quantal content; however, the expected reduction in decay is only $\sim 10 \%$, which may explain why it was not detected. (The expected shortening was calculated from the change in current amplitude and from the average sensitivity of $\tau_{\mathrm{w}}$ to changes in quantal content: $0.28 \mathrm{~ms} / \mathrm{nA}$.) We conclude that delayed release does not contribute detectably to EPSC decay at the calyciform synapse.

\section{Blocking AChE enhances the sensitivity of synaptic currents to changes in quantal content}

If spillover underlies the prolongation of EPSC decay with elevated quantal content, then inhibiting $\mathrm{AChE}$ within the synaptic cleft at this synapse (Olivieri-Sangiacomo et al., 1983) should increase the sensitivity of EPSC decay to changes in quantal content, since it should afford greater opportunity for ACh released in separate quanta to reach overlapping areas of the postsynaptic membrane (Hartzell et al., 1975). We thus repeated the cadmium protocol after inhibiting AChE with either $0.1 \mu \mathrm{M}$ neostigmine or $10 \mu \mathrm{M} \mathrm{ECHO} \mathrm{(similar} \mathrm{results} \mathrm{were} \mathrm{obtained} \mathrm{with} \mathrm{the} \mathrm{two} \mathrm{inhib-}$ itors; see Materials and Methods). Inhibiting AChE prolonged synaptic currents (Zhang et al., 1996); decay time, measured as $\tau_{\mathrm{w}}$, was lengthened from $4.4 \pm 1.2 \mathrm{~ms}$ to $14.4 \pm 10.6 \mathrm{~ms}$, while rise time was not changed (Fig. $4 A 1, A 2, n=8$ cells, $p=0.02$ ). To explore the effects of inhibiting AChE separately on $\alpha 7$-nAChRand $\alpha 3^{*}$-nAChR-mediated currents, we studied the effect of ECHO on $\tau_{\mathrm{f}}$ and $\tau_{\mathrm{s}}$ of biexponentially fitted EPSC decays. Blocking AChE with ECHO increased $\tau_{\mathrm{s}}$ from $9.7 \pm 1.8 \mathrm{~ms}$ to $13.6 \pm$ $5.2 \mathrm{~ms}(n=9, p=0.02)$ but had no effect on $\tau_{\mathrm{f}}(p=1.0)$, as reported originally by Zhang et al. (1996). To increase the resolving power of these experiments, we treated pharmacologically enriched $\alpha 7$-nAChR-EPSCs and $\alpha 3^{*}$-nAChR-EPSCs with AChE inhibitors, and here we saw an effect on both components of decay; $\tau_{\mathrm{s}}$ measured in $\alpha 3^{\star}$-nAChR-EPSCs, was prolonged from $8.0 \pm 2.0 \mathrm{~ms}$ to $13.0 \pm 5.6 \mathrm{~ms}$ after blocking $\mathrm{AChE}(n=12, p=$ 0.01 ; not illustrated), and $\tau_{\mathrm{f}}$, measured as the fast component of $\alpha 7$-nAChR-EPSC decay, was prolonged from $1.5 \pm 0.3 \mathrm{~ms}$ to
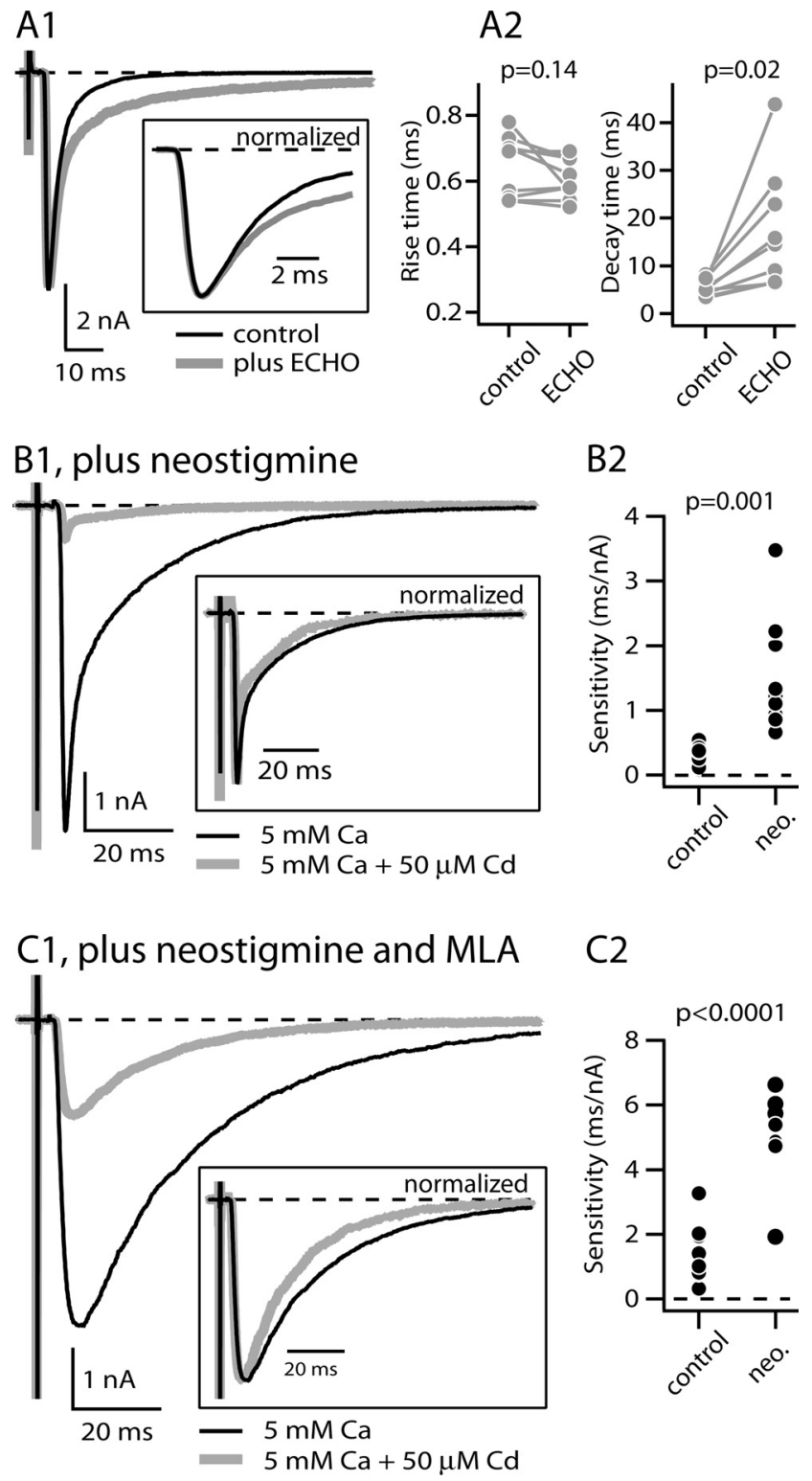

Figure 4. Inhibition of AChE prolongs EPSC decay time and increases sensitivity of decay time to changes in quantal content. A shows effect on EPSC time course of inhibiting AChE with $\mathrm{ECHO}$. $A 1$ shows an example from one cell, where decay time is prolonged but rise time is not evidently changed, and $\boldsymbol{A} \mathbf{2}$ shows the data summary ( $n=8$ cells). $\boldsymbol{B}$ shows that reducing quantal content shortens decay time of EPSCs recorded in neostigmine (B1), as is true for native EPSCS (Fig. 2), and that the sensitivity of decay time to changes in peak amplitude is greater after treatment with neostigmine (neo.) than in its absence (control) (B2). $\boldsymbol{C}$ is similar to $\boldsymbol{B}$, except that recordings were made $50 \mathrm{~nm}$ MLA to produce $\alpha 3^{*}$-nAChR-EPSCs. Again, decay time showed more sensitivity to changes in quantal content after inhibition of AChE (neo.) than in control conditions (C2).

$2.0 \pm 0.4 \mathrm{~ms}(n=5, p=0.0001$; not illustrated). These results extend the original findings of Zhang et al. (1996) and suggest that currents produced by both $\alpha 7$-nAChRs and $\alpha 3^{*}$-nAChRs are prolonged by inhibiting $\mathrm{AChE}$ at the calyciform synapse.

The decay time of EPSCs showed more sensitivity to changes in quantal content after inhibition of AChE than in control conditions. In the example shown in Figure $4 B 1$ decay time of native EPSCs was reduced by $0.76 \mathrm{~ms}$ per $\mathrm{nA}$ of peak current change by cadmium. Overall, the sensitivity of EPSC decay was enhanced more than fivefold compared with conditions with intact $\mathrm{AChE}$ (Fig. 4B2, "control" vs "neo.," $p=0.001$ ). We repeated these 
experiments on $\alpha 3^{\star}$-nAChR EPSCs recorded in the presence of MLA (Fig. 4C); again, sensitivity after blocking AChE was greater than sensitivity in controls (Fig. $4 C 2, p<0.0001)$. Thus, the sensitivity of EPSC decay time to changes in quantal content is increased after inhibition of AChE, both for native EPSCs and for $\alpha 3^{*}$ nAChR-EPSCs. This is consistent with the hypothesis that altering quantal content affects EPSC decay by changing the consequences of spillover.

\section{Channel reopenings cannot explain increased EPSC decay times at high quantal content}

If transmitter release is multivesicular, then elevating quantal content may increase peak ACh concentration and prolong currents due to the repeated opening of nAChR channels near sites of release (Giniatullin et al., 1993). Thus, EPSC prolongation might be caused by reopenings of channels that lie physically close to release sites rather than by openings of naive channels that lie some distance away, i.e., true spillover. Repeated activation of channels should be antagonized by chlorisondamine (el-Bizri and Clarke, 1994; Amador and Dani, 1995), which preferentially blocks open channels and should prevent them from recycling rapidly.

To explore whether channel reopenings contribute to the prolongation of EPSC decay at high quantal content, we asked whether chlorisondamine is more effective at reducing EPSC decay at high quantal content than at low quantal content. We performed these experiments on pharmacologically isolated $\alpha 3^{\star}$-nAChR EPSCs, since these currents show more sensitivity to changes in quantal content than do $\alpha 7$-nAChR-mediated currents. To account for the possibility that chlorisondamine might wash out only slowly after receptor block, the low quantal content conditions were performed first. Figure $5 A$ shows the results of a typical experiment; EPSCs were first recorded at low quantal content, both before and after addition of chlorisondamine; then, after washing out the cadmium and chlorisondamine, they were measured at high quantal content, both before and after addition of chlorisondamine. In this trial chlorisondamine shortened EPSC decay $57 \%$ at low quantal content, and it subsequently shortened EPSC decay at high quantal content by 47\% (Fig. 5B1,B2). Over 6 experiments chlorisondamine shortened EPSC decay by a similar extent at low and at high quantal content ( $47 \pm 15 \%$ vs $43 \pm 15 \%$ block, respectively, Fig. $5 B 3, p=0.7$ ). These results indicate that channel reopening does not contribute detectably to the prolongation of EPSCs at high quantal content; EPSCs decay more slowly at higher quantal content because of the delayed opening of naive channels, as would be expected from spillover of ACh and its action on distant nAChRs. These findings are equally compatible with the possibility that there are no channel reopenings whatsoever and with the possibility that there is a comparable degree of reopening at low and high quantal content.
$5 \mathrm{mMCa}$

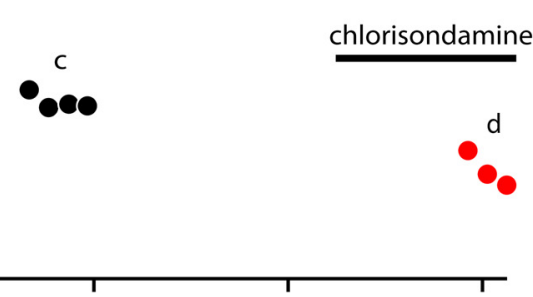

$\sqrt{6}$
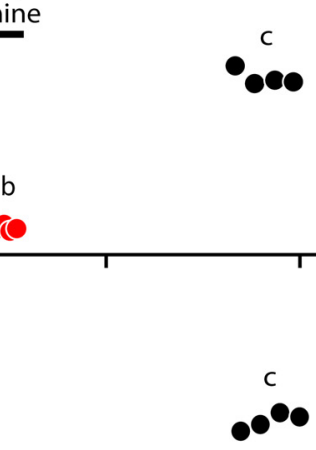

b

d

8

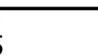

10

Time (min)

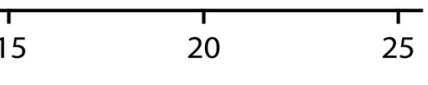

2, high $\mathrm{m}$

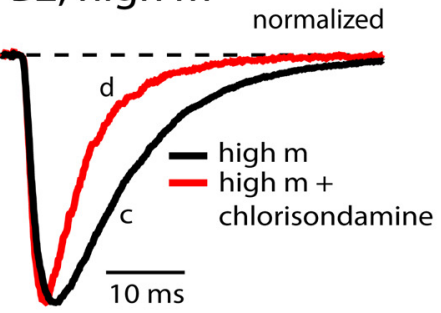

B3

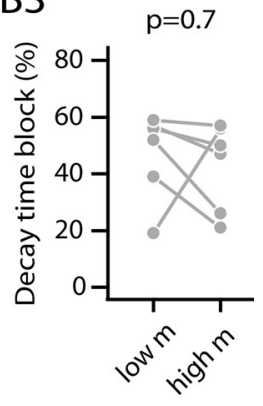

Figure 5. The open channel blocker chlorisondamine reduces $\alpha 3^{*}$-nAChR EPSC decay times equally well at low and at high content and then, after washout of it and cadmium, after chlorisondamine is reapplied at high quantal content. The reduction of EPSC decay at low (B1) and high (B2) quantal content (low $\mathrm{m}$, high $\mathrm{m}$ ) was not different across a sample of 6 cells (B3).

\section{Contributions to synaptic currents from $\alpha 7-\mathrm{nAChRs}$ and} from $\alpha 3^{\star}-n A C h R s$ do not add linearly

The decay of $\alpha 3^{\star}$-nAChR-EPSCs shows 5- to 10-fold more sensitivity to changes in quantal content, measured as $\mathrm{ms} / \mathrm{nA}$, than that of $\alpha 7$-nAChR-EPSCs, as reported above. Surprisingly, when both $\alpha 7$-nAChRs and $\alpha 3^{\star}$-nAChRs are activated by transmitter, as occurs in native conditions, the sensitivity of EPSC decay $\left(0.28 \pm 0.17 \mathrm{~ms} / \mathrm{nA}\right.$, measured as $\left.\Delta \tau_{\mathrm{w}} / \Delta \mathrm{A}\right)$ is modest and only marginally greater than that of the $\alpha 7-\mathrm{nAChR}$-mediated $\tau_{\mathrm{f}}(p=$ 0.03 when compared with $\tau_{\mathrm{f}}$ sensitivity for native EPSCs and $p=$ 0.25 when compared with $\tau_{\mathrm{f}}$ sensitivity for $\alpha 7$-nAChR-enriched EPSCs recorded in $\alpha$-CTx-MII). By contrast, the sensitivity of native EPSC decay was significantly less than that of the $\alpha 3^{*}$ $\mathrm{nAChR} \tau_{\mathrm{s}}$, measured either on native EPSCs $(p=0.003)$ or on $\alpha 3^{\star}$-nAChR-EPSCs recorded in MLA $(p=0.007)$. If $\alpha 7$-nAChRs and $\alpha 3^{\star}$-nAChRs function independently, then the sensitivity of native EPSC decay time to changes in quantal content should be intermediate between that of $\alpha 7$-nAChR-EPSCs $(\sim 0.2 \mathrm{~ms} / \mathrm{nA})$ and that of $\alpha 3^{*}$-nAChR-EPSCs $(\sim 1.0 \mathrm{~ms} / \mathrm{nA})$, but it was evidently not. To confirm that native EPSC decay should show an intermediate degree of sensitivity, assuming linear addition of currents from the two nAChRs, we generated fits to representative $\alpha 7$-nAChR- and $\alpha 3^{*}$-nAChR-EPSCs using a modification of the fitting function described by Bekkers and Clements (1999), 

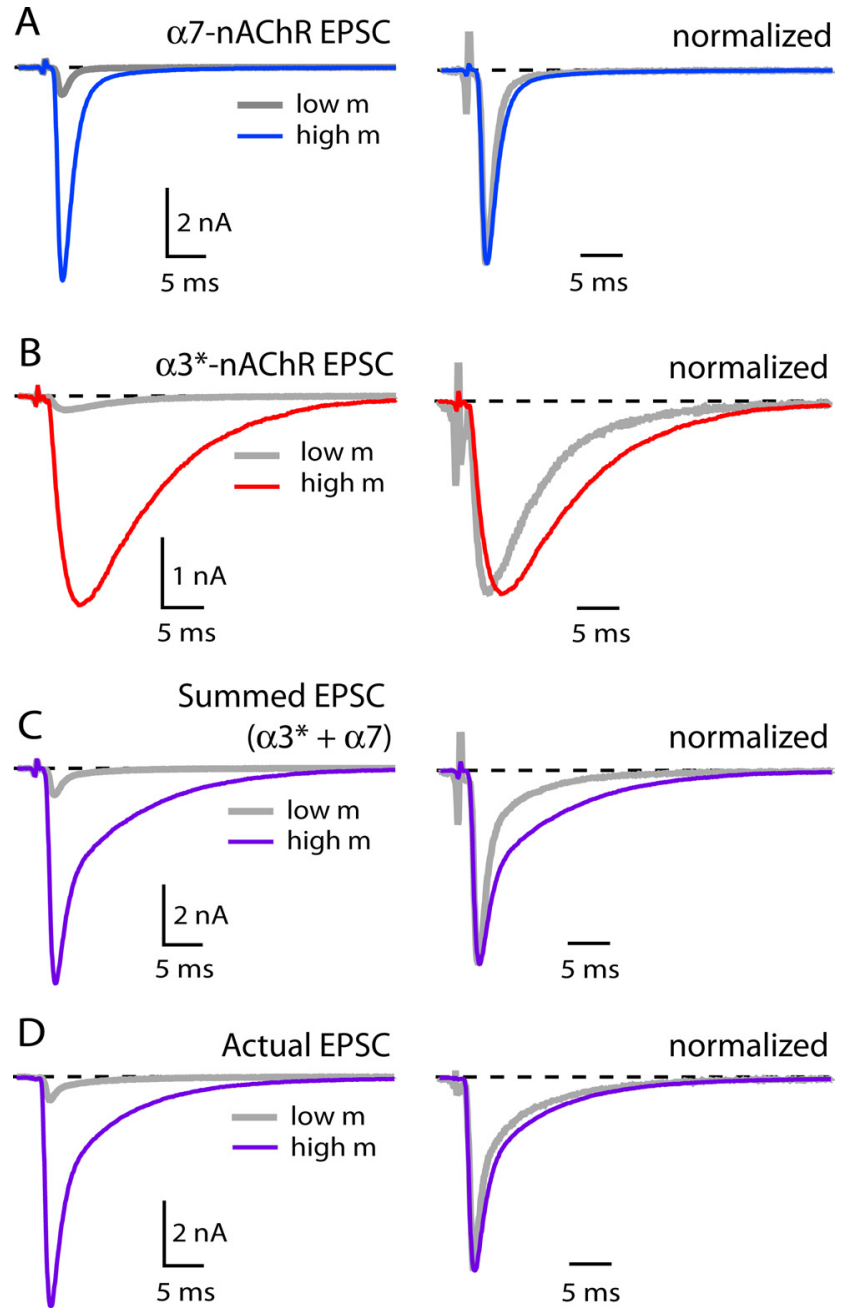

Figure 6. The decay time of simulated EPSCS shows more sensitivity to changes in quantal content than that of native EPSCS. $A-D$, Simulated EPSCS were generated by taking pharmacologically isolated $\alpha 7-n A C h R(A)$ and $\alpha 3^{*}$-nAChREPSCs $(\boldsymbol{B})$, with $\tau$ values that fell within $20 \%$ of the sample median, scaling them to the sample mean amplitude at low and high quantal content, and by then adding the currents to produce "summed" native EPSCs(C). The decay time of summed native EPSCS shows more sensitivity to changes in quantal content than native EPSCS (compare $\boldsymbol{C}$, right, to $\boldsymbol{D}$, right). This comparison suggests that synaptic currents generated by $\alpha 7-n A C h R s$ and $\alpha 3^{*}$-nAChRs do not add linearly when both nAChRs are active. See text for additional discussion.

collected at both low and high quantal content, and then summed the fits (Fig. 6). The decay of summed waveforms (Fig. 6C) indeed showed an intermediate degree of sensitivity to changes in quantal content, $0.57 \pm 0.17 \mathrm{~ms} / \mathrm{nA}(n=3)$, which was greater than the sensitivity of native EPSC decay ( $p=0.04$ by unpaired $t$ test). The sensitivity of summed EPSCs (Fig. 6) to changes in quantal content are not different from the sensitivity of the $\alpha 3^{*}$ nAChR-mediated $\tau_{\mathrm{s}}$ of native EPSCs $(p=0.3)$ or of the $\alpha 3^{*}$ $\mathrm{nAChR}-\mathrm{EPSC} \tau_{\mathrm{s}}$ recorded in MLA $(p=0.2)$. Thus, the sensitivity of $\alpha 3^{\star}$-nAChR current to changes in quantal content should be pronounced in native EPSCs, but it's barely detectable. This can be visualized graphically by comparing Figure $6 C$, right (summed EPSC), and 6D, right (actual EPSC); the native condition (Fig. $6 D$ ) does not replicate the "simulated" one (Fig. $6 C$ ). It is as if $\alpha 3^{\star}$-nAChRs, which contribute significantly to EPSC broadening when acting on their own (Fig. $6 C$, right), contribute less when $\alpha 7$-nAChRs are also available to bind ACh (Fig. $6 D$, right). This may occur because $\alpha 7-\mathrm{nAChRs}$ buffer ACh and prevent it from reaching $\alpha 3^{\star}$-nAChRs: a prediction made by MCell modeling of this synapse (Coggan et al., 2005).

\section{Discussion}

EPSCs at the chick calyciform synapse decay more slowly at higher quantal content. Control experiments rule out a presynaptic basis for this effect, and for $\alpha 3^{\star}$-nAChRs we suggest that the broadening of the EPSC is caused by spillover; by analogy with findings first reported at the neuromuscular junction, ACh released in separate exocytotic events reaches overlapping areas of the postsynaptic membrane, activates nAChRs there, and prolongs and potentiates the response (Hartzell et al., 1975; Magleby and Terrar, 1975). This effect differs from the original reports at the neuromuscular junction in that it occurs in the presence of acetylcholinesterase. An alternative possibility, that the prolongation results from a lengthening of channel open times, seems unlikely given that the time window over which currents are potentiated, $\sim 20 \mathrm{~ms}$ (Fig. $2 \mathrm{~B}$ ), is considerably longer than the longest population of channel opening times observed for $\alpha 3^{\star}$ nAChRs on ciliary neurons, which is $3-4 \mathrm{~ms}$ (McNerney et al., 2000; Nai et al., 2003). These findings extend our previous work (Sargent, 2009), which showed that extrasynaptic nAChRs dominate the response to nerve-released ACh. It is not clear whether extrasynaptic receptors at this synapse are activated focally by ectopic release (Coggan et al., 2005) and/or by spillover following active zone-based release (Nguyen and Sargent, 2002). An active zone-based model of release requires spillover of ACh to explain transmission at this synapse, and here we show that spillover indeed occurs.

The effect of changing quantal content upon $\alpha 7-n A C h R-$ mediated current decay is barely one-tenth of the magnitude of the effect upon $\alpha 3^{*}$-nAChR-mediated current, and it occurs without a detectable change in rise time. The potentiation of $\alpha 7$-nAChR-mediated currents is confined to a 1-2 ms time window (Fig. 2C2a): approximately a tenth of the time window over which $\alpha 3^{\star}$-nAChR-mediated currents are potentiated. We suggest that spillover does not underlie the broadening of current over this restricted time frame. A more likely possibility is that the prolongation of $\alpha 7$-nAChR-mediated current results from increased occupancy of longer channel opening states; $\alpha 7$-nAChR channels on chick ciliary neurons display multiple populations of open times, including intermediate and long states with lifetimes of $\sim 0.7$ and $\sim 2 \mathrm{~ms}$ (Nai et al., 2003); possibly, average open time is prolonged when the receptor is activated by more agonist molecules (Beato et al., 2002; Rayes et al., 2009; Williams et al., 2011), as might occur when quantal content is elevated. Additional study will be required to learn whether elevated [ACh] is likely to result from elevated quantal content at this synapse; this would be expected if release is active zone based and multivesicular at high probability of release (Wadiche and Jahr, 2001).

The ability of $\alpha 3^{\star}$-nAChRs, but less so $\alpha 7$-nAChRs, to report spillover of ACh at higher quantal content is not likely to have arisen because of differences in the distribution of nAChRs, but we cannot rule out this possibility with certainty. Both $\alpha 3^{*}$ nAChRs and $\alpha 7$-nAChRs are intermixed and appear to be distributed diffusely on somatic spines (Fig. 1) (Horch and Sargent, 1995; Conroy et al., 2003); these receptors, and not those located at PSDs, are responsible for the bulk of the synaptic current (Sargent, 2009).

The anatomy of the chick calyciform synapse (Fig. 1) is well suited for spillover of ACh to feature prominently in transmission (Barbour and Häusser, 1997): (1) the area of apposition between terminal and target cell is substantial, which will force 
ACh to travel a considerable distance before escaping the cleft (Kinney et al., 1997); (2) nAChRs are widely distributed on spines (Horch and Sargent, 1995; Shoop et al., 1999; Conroy et al., 2003); and (3) release sites may be widely distributed over the spine membrane (Coggan et al., 2005). Given this, it is worth exploring why $\alpha 7$-nAChRs show less tendency to respond to spillover. A complete picture of the channel properties of native $\alpha 7$-nAChRs has yet to emerge; however, chimeric $\alpha 7$-nAChR-5$\mathrm{HT}_{3 \mathrm{~A}}$ receptors, and perhaps native $\alpha 7-\mathrm{nAChRs}$, are efficiently activated only when three of their binding sites are occupied (Rayes et al., 2009), which means that their ability to respond to ACh release should decline steeply with distance from a release site.

Our findings replicate those reported for multisite glutamatergic synapses in the CNS (Takahashi et al., 1995; Otis et al., 1996; Silver et al., 1996) and those where independent inputs to a target cell are close enough to allow for cooperative activation of receptors (Carter and Regehr, 2000; Arnth-Jensen et al., 2002; Balakrishnan et al., 2009). The time course of nicotinic synaptic currents recorded from rat submandibular ganglion cells is not altered upon the addition of sufficient cadmium to reduce the EPSC by $90 \%$ (Callister and Walmsley, 1996), suggesting that at this synapse cooperation between independent release events does not occur. This difference could arise because the relationship between release sites and nAChR clusters is more conventional in the rat system, with active zones aligned with high density nAChR clusters (McCann et al., 2008).

Giniatullin et al. (1993) found that EPSC decay at the frog neuromuscular junction lengthened with increasing quantal content, but only after quantal content exceeded $\sim 100$; they argued that the prolongation in EPSC decay is driven by the onset of multivesicular release and is caused by repeated opening of focal $\mathrm{nAChR}$ channels. However, at the calyciform synapse our results with the open channel blocker chlorisondamine suggest that reopening of nAChR channels cannot explain EPSC broadening at high quantal content; rather, the broadening presumably represents naive receptor channels that open late, presumably because they are distant from release sites.

$\alpha 7$-nAChRs may not report spillover in our system; to the contrary, they appear to reduce the tendency of $\alpha 3^{\star}$-nAChRs to report spillover. This property was predicted by an MCell modeling study of transmission at this synapse (Coggan et al., 2005); $\alpha 7$-nAChRs may be optimized in this system to buffer ACh and regulate its availability to $\alpha 3^{\star}$-nAChRs because of their high copy number (Chiappinelli and Giacobini, 1978; Conroy et al., 1992; Pugh et al., 1995), because each $\alpha 7$-nAChR oligomer may bind five ACh molecules (Palma et al., 1996; Rayes et al., 2009), and because $\alpha 7$-nAChRs and $\alpha 3^{\star}$-nAChRs are intermixed on the surface of spines (Fig. 1) (Horch and Sargent, 1995; Conroy et al., 2003). The possibility that $\alpha 7$-nAChR activation negatively regulates $\alpha 3^{\star}$-nAChR function via a calcium-mediated intracellular signaling pathway, as it does $\mathrm{GABA}_{\mathrm{A}}$ receptors in other systems (Wanaverbecq et al., 2007; Zhang and Berg, 2007), is unlikely, since our recordings are made with elevated EGTA in the internal solution, which blocks the pathway regulating $\mathrm{GABA}_{\mathrm{A}}$ receptor function. We speculate that $\alpha 7$-nAChRs, which are found in perisynaptic locations elsewhere in the nervous system (Fabian-Fine et al., 2001; Jones and Wonnacott, 2004) and which are numerous in the brain, may buffer ACh and regulate its availability to non- $\alpha 7$-nAChRs. This proposed role is analogous to that demonstrated for the acetylcholine binding protein of the mollusc Lymnea stagnalis (Smit et al., 2001), a secreted protein with high homology to the extracellular domain of $\alpha 7$-nAChRs.
What is the relevance of this work to the ongoing dialogue about paracrine nicotinic transmission in the CNS? One of the enduring questions regarding central $\mathrm{nAChRs}$ is how they are activated by endogenous transmitter. An accompanying set of questions includes whether $\mathrm{ACh}$ is the endogenous ligand for nAChRs (Papke et al., 1996; Alkondon et al., 1997, 2004) and whether modulation of neuronal signaling in adult brain is the principal function of nAChRs (McLaughlin et al., 2003; Chernyavsky et al., 2004; Liu et al., 2006; Morishita et al., 2010). The number of instances of functionally characterized fast nicotinic synapses in the CNS is modest, and paracrine mechanisms may be at play (Descarries et al., 1997; Dani and Bertrand, 2007; Ren et al., 2011). Might ACh diffuse short distances $(\sim 1-10 \mu \mathrm{m})$ from its release site to act on nearby nAChRs? In conjunction with a sufficient number of nAChRs, even micromolar ACh may be capable of opening a sufficient number of nAChR channels to produce a meaningful signal. This scenario has been illustrated in the medial habenula by Guo and Lester (2007); there, non- $\alpha 7$ nAChRs with a subunit composition similar to nAChRs in the ciliary ganglion (with $\alpha 3, \alpha 5, \beta 2$, and $\beta 4$ possibly present in individual $\mathrm{nAChR}$ pentamers) respond to low concentrations of $\mathrm{ACh}$, and possibly to choline, in a sustained fashion.

Many cholinergic boutons in brain have no associated postsynaptic elements (Descarries et al., 1997), and many immunocytochemically demonstrable nAChRs have no apposing presynaptic elements (Jones and Wonnacott, 2004); the details of what lies between looms as a "missing link" in our understanding of endogenous nicotinic signaling in brain. Further work should be done on the anatomical arrangement of cholinergic boutons and "nonsynaptic" nAChRs: 3D reconstructions are needed, combined with high resolution visualization of nAChRs (Jones and Wonnacott, 2004). This, coupled with additional information about the levels of AChE present, would then permit a model to be constructed. Finally, to gain acceptability, one will need to stimulate cholinergic boutons and demonstrate the consequences of ACh release on nearby cells bearing nAChRs (Wanaverbecq et al., 2007; Ren et al., 2011).

\section{References}

Albuquerque EX, Pereira EF, Alkondon M, Rogers SW (2009) Mammalian nicotinic acetylcholine receptors: from structure to function. Physiol Rev 89:73-120.

Alkondon M, Pereira EF, Cortes WS, Maelicke A, Albuquerque EX (1997) Choline is a selective agonist of $\alpha 7$ nicotinic acetylcholine receptors in the rat brain neurons. Eur J Neurosci 9:2734-2742.

Alkondon M, Pereira EF, Yu P, Arruda EZ, Almeida LE, Guidetti P, Fawcett WP, Sapko MT, Randall WR, Schwarcz R, Tagle DA, Albuquerque EX (2004) Targeted deletion of the kynurenine aminotransferase II gene reveals a critical role of endogenous kynurenic acid in the regulation of synaptic transmission via $\alpha 7$ nicotinic receptors in the hippocampus. J Neurosci 24:4635-4648.

Amador M, Dani JA (1995) Mechanism for modulation of nicotinic acetylcholine receptors that can influence synaptic transmission. J Neurosci 15:4525-4532.

Arnth-Jensen N, Jabaudon D, Scanziani M (2002) Cooperation between independent hippocampal synapses is controlled by glutamate uptake. Nat Neurosci 5:325-331.

Atluri PP, Regehr WG (1998) Delayed release of neurotransmitter from cerebellar granule cells. J Neurosci 18:8214-8227.

Balakrishnan V, Kuo SP, Roberts PD, Trussell LO (2009) Slow glycinergic transmission mediated by transmitter pooling. Nat Neurosci 12:286-294.

Barbour B, Häusser M (1997) Intersynaptic diffusion of neurotransmitter. Trends Neurosci 20:377-384.

Beato M, Groot-Kormelink PJ, Colquhoun D, Sivilotti LG (2002) Openings of the rat recombinant $\alpha 1$ homomeric glycine receptor as a function of the number of agonist molecules bound. J Gen Physiol 119:443-466.

Bekkers JM, Clements JD (1999) Quantal amplitude and quantal variance of 
strontium-induced asynchronous EPSCs in rat dentate granule neurons. J Physiol 516:227-248.

Betz W, Sakmann B (1973) Effects of proteolytic enzymes on function and structure of frog neuromuscular junctions. J Physiol 230:673-688.

Bouzat C, Bartos M, Corradi J, Sine SM (2008) The interface between extracellular and transmembrane domains of homomeric Cys-loop receptors governs open-channel lifetime and rate of desensitization. J Neurosci 28:7808-7819.

Callister RJ, Walmsley B (1996) Amplitude and time course of evoked and spontaneous synaptic currents in rat submandibular ganglion cells. J Physiol 490:149-157.

Carter AG, Regehr WG (2000) Prolonged synaptic currents and glutamate spillover at the parallel fiber to stellate cell synapse. J Neurosci 20: 4423-4434.

Chernyavsky AI, Arredondo J, Marubio LM, Grando SA (2004) Differential regulation of keratinocyte chemokinesis and chemotaxis through distinct nicotinic receptor subtypes. J Cell Sci 117:5665-5679.

Chiappinelli VA, Giacobini E (1978) Time course of appearance of alphabungarotoxin binding sites during development of chick ciliary ganglion and iris. Neurochem Res 3:465-478.

Coggan JS, Bartol TM, Esquenazi E, Stiles JR, Lamont S, Martone ME, Berg DK, Ellisman MH, Sejnowski TJ (2005) Evidence for ectopic neurotransmission at a neuronal synapse. Science 309:446-451.

Conroy WG, Vernallis AB, Berg DK (1992) The $\alpha 5$ gene product assembles with multiple acetylcholine receptor subunits to form distinctive receptor subtypes in brain. Neuron 9:679-691.

Conroy WG, Liu Z, Nai Q, Coggan JS, Berg DK (2003) PDZ-containing proteins provide a functional postsynaptic scaffold for nicotinic receptors in neurons. Neuron 38:759-771.

Dani JA, Bertrand D (2007) Nicotinic acetylcholine receptors and nicotinic cholinergic mechanisms of the central nervous system. Annu Rev Pharmacol Toxicol 47:699-729.

Descarries L, Gisiger V, Steriade M (1997) Diffuse transmission by acetylcholine in the CNS. Prog Neurobiol 53:603-625.

el-Bizri H, Clarke PB (1994) Blockade of nicotinic receptor-mediated release of dopamine from striatal synaptosomes by chlorisondamine and other nicotinic antagonists administered in vitro. $\mathrm{Br} \mathrm{J}$ Pharmacol 111:406-413.

Fabian-Fine R, Skehel P, Errington ML, Davies HA, Sher E, Stewart MG, Fine A (2001) Ultrastructural distribution of the alpha7 nicotinic acetylcholine receptor subunit in rat hippocampus. J Neurosci 21:7993-8003.

Genzen JR, McGehee DS (2003) Short- and long-term enhancement of excitatory transmission in the spinal cord dorsal horn by nicotinic acetylcholine receptors. Proc Natl Acad Sci U S A 100:6807-6812.

Giniatullin RA, Khazipov RN, Vyskocil F (1993) A correlation between quantal content and decay time of endplate currents in frog muscles with intact cholinesterase. J Physiol 466:95-103.

Gotti C, Clementi F (2004) Neuronal nicotinic receptors: from structure to pathology. Prog Neurobiol 74:363-396.

Guo X, Lester RA (2007) $\mathrm{Ca}^{2+}$ flux and signaling implications by nicotinic acetylcholine receptors in rat medial habenula. J Neurophysiol 97:83-92.

Hagler DJ Jr, Goda Y (2001) Properties of synchronous and asynchronous release during pulse train depression in cultured hippocampal neurons. J Neurophysiol 85:2324-2334.

Hall ZW, Kelly RB (1971) Enzymatic detachment of endplate acetylcholinesterase from muscle. Nat New Biol 232:62-63.

Hartzell HC, Kuffler SW, Yoshikami D (1975) Post-synaptic potentiation: interaction between quanta of acetylcholine at the skeletal neuromuscular synapse. J Physiol 251:427-463.

Horch HL, Sargent PB (1995) Perisynaptic surface distribution of multiple classes of nicotinic acetylcholine receptors on neurons in the chicken ciliary ganglion. J Neurosci 15:7778-7795.

Jacob MH, Berg DK (1983) The ultrastructural localization of $\alpha$-bungarotoxin binding sites in relation to synapses on chick ciliary ganglion neurons. J Neurosci 3:260-271.

Jones IW, Wonnacott S (2004) Precise localization of $\alpha 7$ nicotinic acetylcholine receptors on glutamatergic axon terminals in the rat ventral tegmental area. J Neurosci 24:11244-11252.

Jones IW, Bolam JP, Wonnacott S (2001) Presynaptic localisation of the nicotinic acetylcholine receptor $\beta 2$ subunit immunoreactivity in rat nigrostriatal dopaminergic neurones. J Comp Neurol 439:235-247.
Kawai H, Lazar R, Metherate R (2007) Nicotinic control of axon excitability regulates thalamocortical transmission. Nat Neurosci 10:1168-1175.

Kawaja MD, Flumerfelt BA, Hrycyshyn AW (1990) A comparison of the subnuclear and ultrastructural distribution of acetylcholinesterase and choline acetyltransferase in the rat interpeduncular nucleus. Brain Res Bull 24:517-523.

Kinney GA, Overstreet LS, Slater NT (1997) Prolonged physiological entrapment of glutamate in the synaptic cleft of cerebellar unipolar brush cells. J Neurophysiol 78:1320-1333.

Liu Z, Neff RA, Berg DK (2006) Sequential interplay of nicotinic and GABAergic signaling guides neuronal development. Science 314: $1610-1613$.

Loring RH, Zigmond RE (1987) Ultrastructural distribution of ${ }^{125}$ I-toxin F binding sites on chick ciliary neurons: synaptic localization of a toxin that blocks ganglionic nicotinic receptors. J Neurosci 7:2153-2162.

Magleby KL, Terrar DA (1975) Factors affecting the time course of decay of end-plate currents: a possible cooperative action of acetylcholine on receptors at the frog neuromuscular junction. J Physiol 244:467-495.

Mansvelder HD, Keath JR, McGehee DS (2002) Synaptic mechanisms underlie nicotine-induced excitability of brain reward areas. Neuron 33:905-919.

McCann CM, Tapia JC, Kim H, Coggan JS, Lichtman JW (2008) Rapid and modifiable neurotransmitter receptor dynamics at a neuronal synapse in vivo. Nat Neurosci 11:807-815.

McLaughlin T, Torborg CL, Feller MB, O’Leary DD (2003) Retinotopic map refinement requires spontaneous retinal waves during a brief critical period of development. Neuron 40:1147-1160.

McNerney ME, Pardi D, Pugh PC, Nai Q, Margiotta JF (2000) Expression and channel properties of $\alpha$-bungarotoxin-sensitive acetylcholine receptors on chick ciliary and choroid neurons. J Neurophysiol 84:1314-1329.

Mizukawa K, McGeer PL, Tago H, Peng JH, McGeer EG, Kimura H (1986) The cholinergic system of the human hindbrain studied by choline acetyltransferase immunohistochemistry and acetylcholinesterase histochemistry. Brain Res 379:39-55.

Morishita H, Miwa JM, Heintz N, Hensch TK (2010) Lynx1, a cholinergic brake, limits plasticity in adult visual cortex. Science 330:1238-1240.

Moroni M, Zwart R, Sher E, Cassels BK, Bermudez I (2006) $\alpha 4 \beta 2$ Nicotinic receptors with high and low acetylcholine sensitivity: pharmacology, stoichiometry, and sensitivity to long-term exposure to nicotine. Mol Pharmacol 70:755-768.

Nai Q, McIntosh JM, Margiotta JF (2003) Relating neuronal nicotinic acetylcholine receptor subtypes defined by subunit composition and channel function. Mol Pharmacol 63:311-324.

Nelson ME, Kuryatov A, Choi CH, Zhou Y, Lindstrom J (2003) Alternate stoichiometries of $\alpha 4 \beta 2$ nicotinic acetylcholine receptors. Mol Pharmacol 63:332-341.

Nguyen D, Sargent PB (2002) Synaptic vesicle recycling at two classes of release sites in giant nerve terminals of the embryonic chicken ciliary ganglion. J Comp Neurol 448:128-137.

Oleskevich S, Walmsley B (2002) Synaptic transmission in the auditory brainstem of normal and congenitally deaf mice. J Physiol 540:447-455.

Olivieri-Sangiacomo C, Del Fà A, Gangitano C (1983) Acetylcholinesterase localization at synapses in chick embryo ciliary ganglion. Experientia 39:598-600.

Otis TS, Wu YC, Trussell LO (1996) Delayed clearance of transmitter and the role of glutamate transporters at synapses with multiple release sites. J Neurosci 16:1634-1644.

Otsu Y, Shahrezaei V, Li B, Raymond LA, Delaney KR, Murphy TH (2004) Competition between phasic and asynchronous release for recovered synaptic vesicles at developing hippocampal autaptic synapses. J Neurosci 24:420-433.

Palma E, Bertrand S, Binzoni T, Bertrand D (1996) Neuronal nicotinic $\alpha 7$ receptor expressed in Xenopus oocytes presents five putative binding sites for methyllycaconitine. J Physiol 491:151-161.

Papke RL, Bencherif M, Lippiello P (1996) An evaluation of neuronal nicotinic acetylcholine receptor activation by quaternary nitrogen compounds indicates that choline is selective for the $\alpha 7$ subtype. Neurosci Lett 213:201-204.

Pugh PC, Corriveau RA, Conroy WG, Berg DK (1995) Novel subpopulation of neuronal acetylcholine receptors among those binding $\alpha$-bungarotoxin. $\mathrm{Mol}$ Pharmacol 47:717-725. 
Rang HP (1981) The characteristics of synaptic currents and responses to acetylcholine of rat submandibular ganglion cells. J Physiol 311:23-55.

Rayes D, De Rosa MJ, Sine SM, Bouzat C (2009) Number and locations of agonist binding sites required to activate homomeric Cys-loop receptors. J Neurosci 29:6022-6032.

Ren J, Qin C, Hu F, Tan J, Qiu L, Zhao S, Feng G, Luo M (2011) Habenula "cholinergic" neurons corelease glutamate and acetylcholine and activate postsynaptic neurons via distinct transmission modes. Neuron 69: $445-452$.

Rogers M, Sargent PB (2003) Rapid activation of presynaptic nicotinic acetylcholine receptors by nerve-released transmitter. Eur J Neurosci 18:2946-2956.

Sargent PB (2009) Nicotinic receptors concentrated in the subsynaptic membrane do not contribute significantly to synaptic currents at an embryonic synapse in the chicken ciliary ganglion. J Neurosci 29:3749-3759.

Sarter M, Parikh V, Howe WM (2009) Phasic acetylcholine release and the volume transmission hypothesis: time to move on. Nat Rev Neurosci 10:383-390.

Shoop RD, Martone ME, Yamada N, Ellisman MH, Berg DK (1999) Neuronal acetylcholine receptors with $\alpha 7$ subunits are concentrated on somatic spines for synaptic signaling in embryonic chick ciliary ganglia. J Neurosci 19:692-704.

Shoop RD, Esquenazi E, Yamada N, Ellisman MH, Berg DK (2002) Ultrastructure of a somatic spine mat for nicotinic signaling in neurons. J Neurosci 22:748-756.

Silver RA, Cull-Candy SG, Takahashi T (1996) Non-NMDA glutamate receptor occupancy and open probability at a rat cerebellar synapse with single and multiple release sites. J Physiol 494:231-250.

Smit AB, Syed NI, Schaap D, van Minnen J, Klumperman J, Kits KS, Lodder $\mathrm{H}$, van der Schors RC, van Elk R, Sorgedrager B, Brejc K, Sixma TK, Geraerts WP (2001) A glia-derived acetylcholine-binding protein that modulates synaptic transmission. Nature 411:261-268.

Takahashi M, Kovalchuk Y, Attwell D (1995) Pre- and postsynaptic deter- minants of EPSC waveform at cerebellar climbing fiber and parallel fiber to Purkinje cell synapses. J Neurosci 15:5693-5702.

Traynelis SF (1998) Software-based correction of single compartment series resistance errors. J Neurosci Methods 86:25-34.

Ullian EM, McIntosh JM, Sargent PB (1997) Rapid synaptic transmission in the avian ciliary ganglion is mediated by two distinct classes of nicotinic receptors. J Neurosci 17:7210-7219.

Umbriaco D, Watkins KC, Descarries L, Cozzari C, Hartman BK (1994) Ultrastructural and morphometric features of the acetylcholine innervation in adult rat parietal cortex: an electron microscopic study in serial sections. J Comp Neurol 348:351-373.

Vizi ES, Lendvai B (1999) Modulatory role of presynaptic nicotinic receptors in synaptic and non-synaptic chemical communication in the central nervous system. Brain Res Brain Res Rev 30:219-235.

Wadiche JI, Jahr CE (2001) Multivesicular release at climbing fiberPurkinje cell synapses. Neuron 32:301-313.

Wanaverbecq N, Semyanov A, Pavlov I, Walker MC, Kullmann DM (2007) Cholinergic axons modulate GABAergic signaling among hippocampal interneurons via postsynaptic $\alpha 7$ nicotinic receptors. J Neurosci 27: 5683-5693.

Williams DK, Stokes C, Horenstein NA, Papke RL (2011) The effective opening of nicotinic acetylcholine receptors with single agonist binding sites. J Gen Physiol 137:369-384.

Zhang J, Berg DK (2007) Reversible inhibition of GABAA receptors by $\alpha 7$ containing nicotinic receptors on the vertebrate postsynaptic neurons. J Physiol 579:753-763.

Zhang ZW, Coggan JS, Berg DK (1996) Synaptic currents generated by neuronal acetylcholine receptors sensitive to $\alpha$-bungarotoxin. Neuron 17: 1231-1240.

Zwart R, Vijverberg HP (1998) Four pharmacologically distinct subtypes of $\alpha 4 \beta 2$ nicotinic acetylcholine receptor expressed in Xenopus laevis oocytes. Mol Pharmacol 54:1124-1131. 